Vol.16, No. 58, January, 2021, 127-153

\title{
FINDING A CORRELATION BETWEEN THE INTERIOR DESIGN AND THE URBAN CHARACTER.
}

\author{
Sahar Ezz EL Arab Ramadan \\ Department of Architecture, Higher Technological Institute, Cairo, Egypt. \\ E-mail: saharezz_1@hotmail.com
}

\begin{abstract}
:
Traditional Nubian architecture came to meet the needs of its users, and benefited from the capabilities of previous civilizations in terms of local building materials and building methods. However, the exposure of the people of Nubia to leaving their villages for fear of drowning resulting from the high level of the Nile River affected their living and social lives greatly, as They chose areas for living close to Aswan and similar to their original environment in terms of proximity to the Nile River, such as the areas of West Aswan and the village of Ahab Sohaila, and we find that the Nubians preserved in these dwellings on their Nubian style and the shape of their internal architecture that met all their needs, but the second migration that came at the time of the construction of the High Dam took place In which The displacement of the rest of the Nubians to new places, which were in their beginning, buildings consisting of one floor with flat concrete roofs, and they were developed and raised more than one floor later.
\end{abstract}

On the other hand, and the demand of the people of Nubia to return to their old lands, the state made a project for them in the Karkar Valley, except that the displacement of the people of Old Nubia, which took place from their heritage villages to north of Aswan, had the greatest impact in the form of their homes and a change in the architectural vocabulary that distinguished them from others. From the Egyptian environment, where the state began once again to rebuild homes for them around Lake Nasser and settle them in the Karkar Valley area, but there are several drawbacks that affected the interior design For these dwellings and in some architectural vocabulary that some of them have been discarded or reproduced in an expensive manner within the internal housing spaces, the dwellings have become unsuitable for many of them, especially for the educated social group with a university level of education.

The interior design has a great and remarkable role in the designs of the interior spaces in the Nuba dwellings after the displacement, with the aim of restoring the lost heritage features and aesthetics so that the interior design becomes a true picture expressing the human civilization and culture so that both the internal architecture and the external urbanization go in one direction to confirm the urban and heritage character of the place with emphasis The personality of the surrounding environment, so the researcher made use of the vocabulary of the urban character of Aswan within the internal design elements of the housing, after taking advantage of the descriptive and analytical approach of research to provide an applied approach that includes proposed design solutions to develop the interior design of Aswan housing by making use of the correct design determinants that have been reached From the analytical approach within the framework of the proposed design program for the needs of each family, which helps to achieve a good civilized and cultural character of the internal spaces. 


\section{KEYWORDS: Interior Design, Interior Surface Treatments, Urban Character, Future Needs, and Architecture Vocabulary.}

إيجاد علاقة تزابطية بين التصميم الداخلى والطابع الحضرى ـ

$$
\text { سحر عز العرب رمضان سيا }
$$

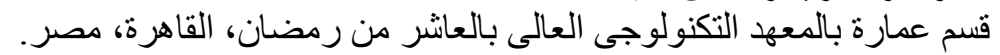

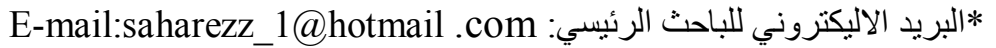

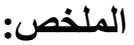

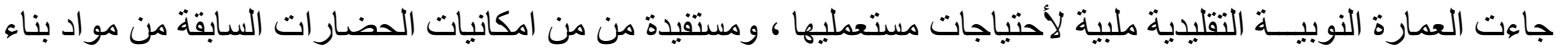

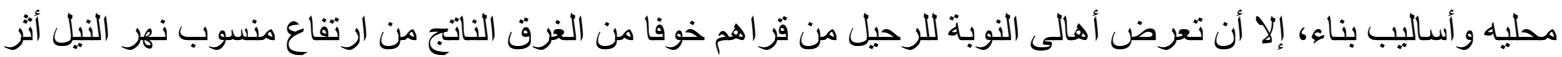

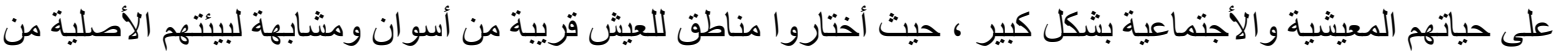

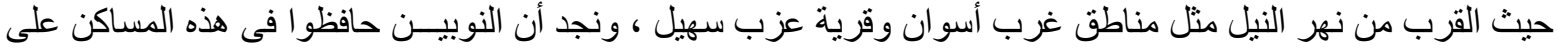

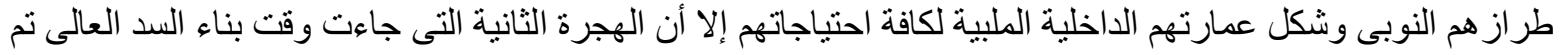

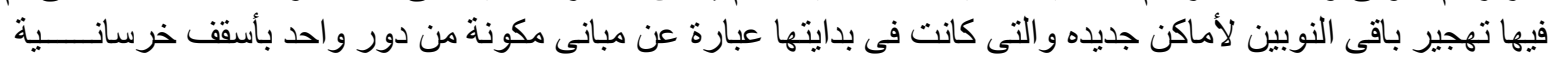

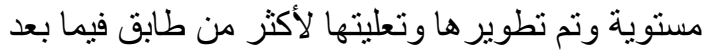

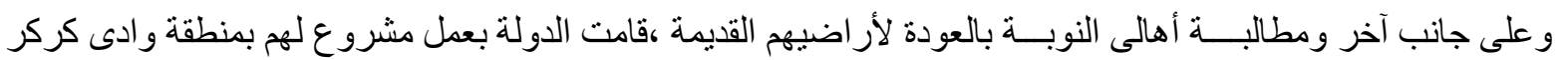

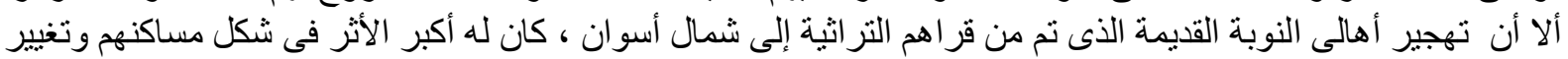

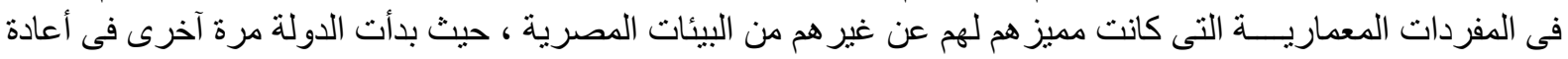

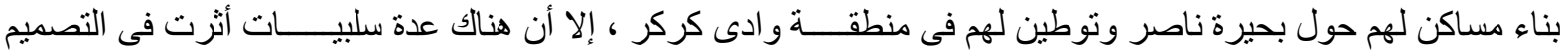

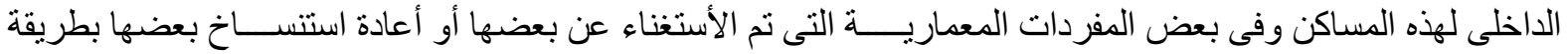

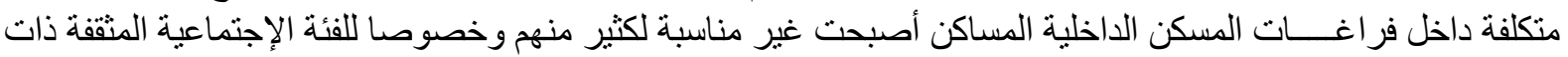

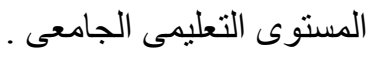

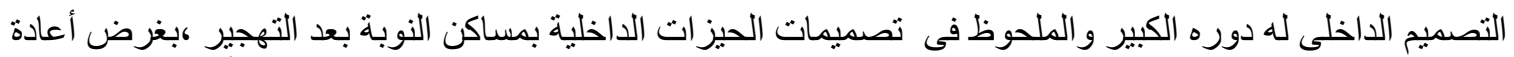

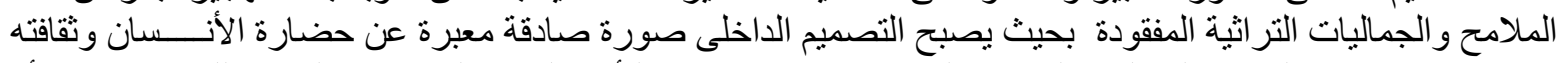

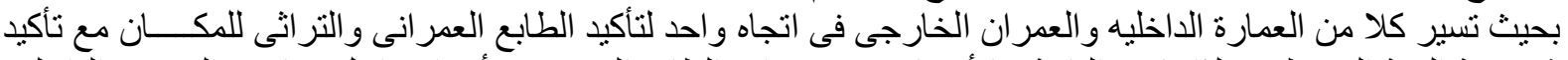

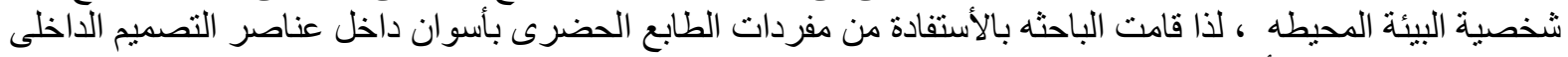

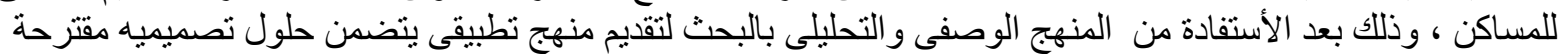

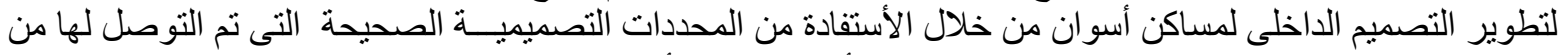

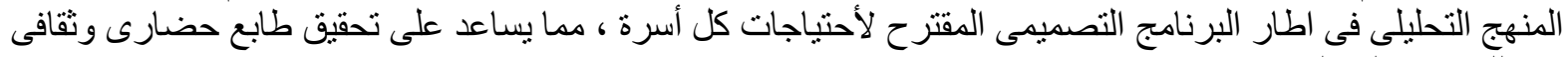

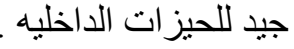

الكلمات المفتاحية: التصميم الداخلى، معالجات الأسطح الداخليـــــة، الطابع الحضرى، الاحتياجات المستقبليــــة، ومفردات العمارة .

المقدمة

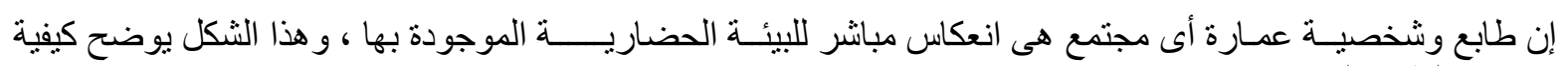
استمر ار الطابع المعمارى .

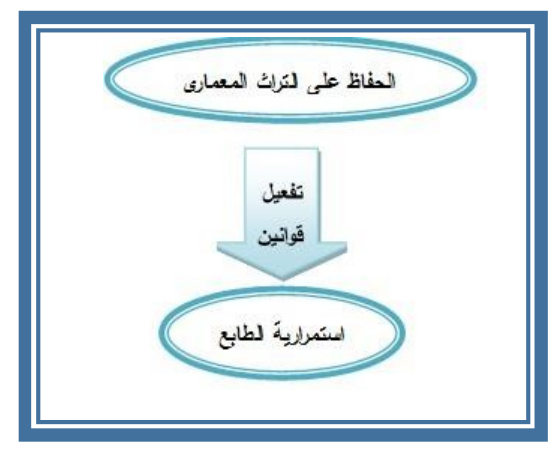




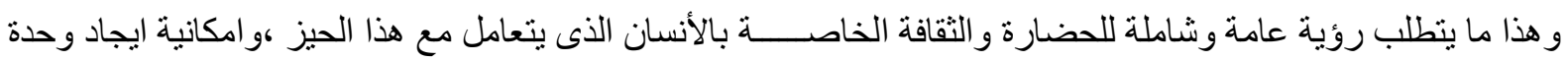

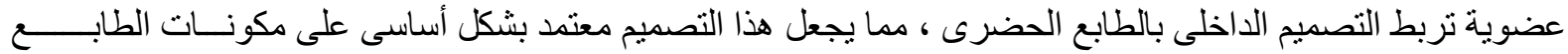
الحضرى من حيث الزخارف و العناصر و الخامات الطبيعية ،وكنللك تأثير ها على تلبية الأحتياجات المستقبلية مما يعمل على لئى

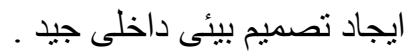

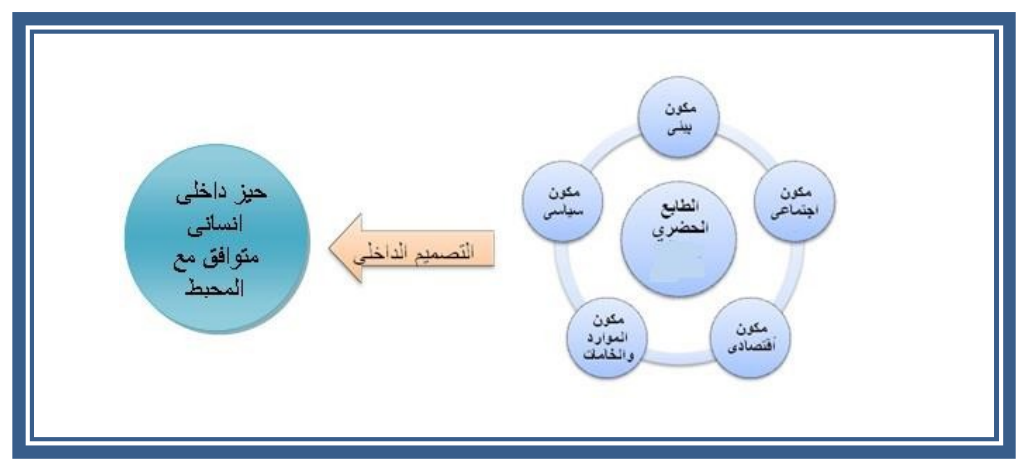

شكل (1 ) مكونات الطابع الحضرى و علاقته بالتصميم الاخلى .

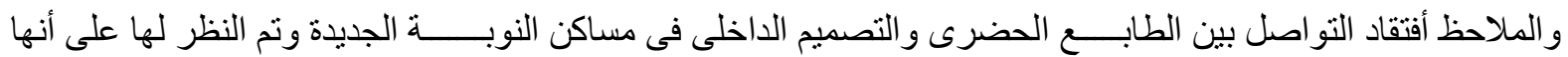

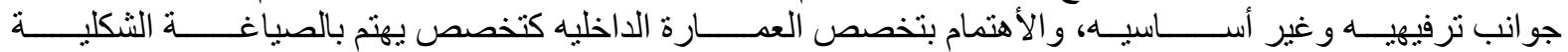
و الوظيفية لكافة عناصر الفر اغ الداخلى ساهم فى أن تكون العمارة الداخليه معبرة بشكل دقيق عن حضارة المكان و البيـــئة

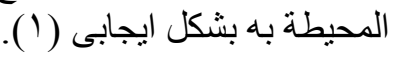

أهمية البحث

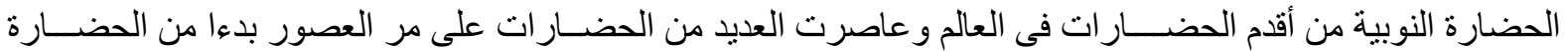

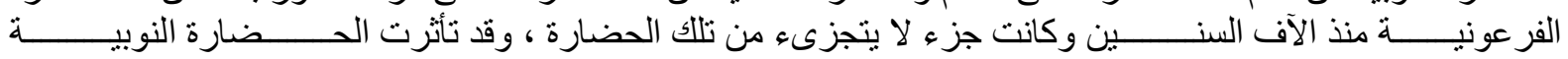

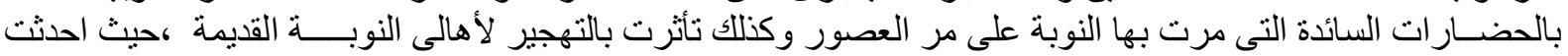

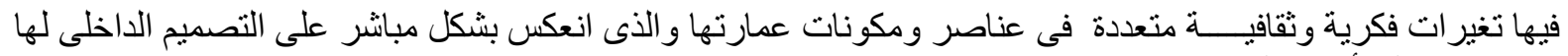

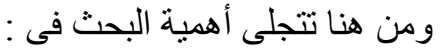

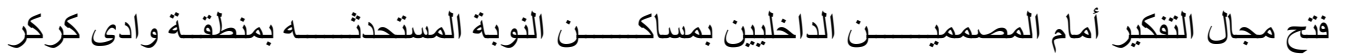
للوصول لتنكيلات تصميمـات داخليــة جيدة معاصرة و أكثر أرتباطا بالطابع الحضرى و الثقافى للبيئة

الأستفادة من عناصر البيئة المحيطة داخل عناصر ومكونات التصميم الداخلى داخل نمــاذج المســـاكن الأستفادة من . المبطة

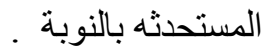

• • توظيف التصميم الداخلى لتهيئة الحيز ات الداخلية بكفاءة وفقا للمفردات المعمارية المستحدثة بالمساكن .

\section{مشكلة البحث}

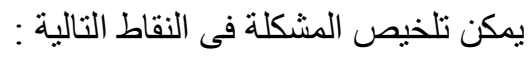

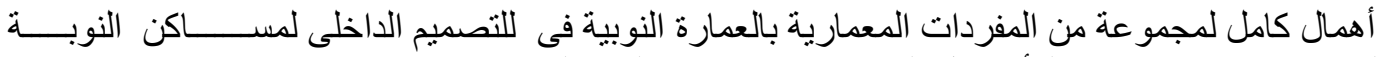

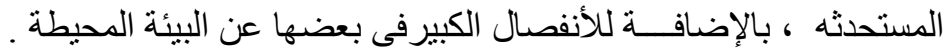

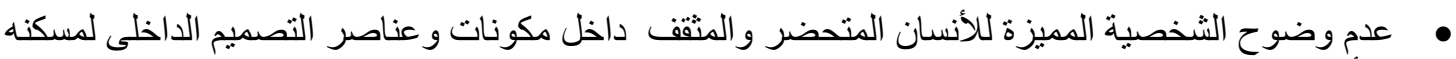

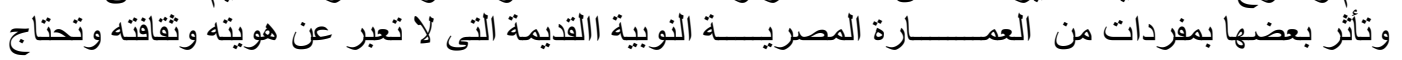

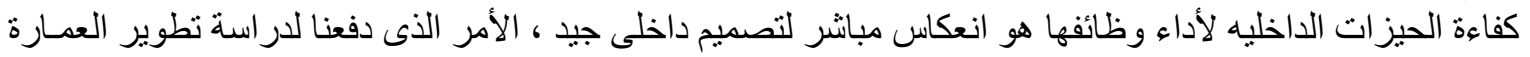

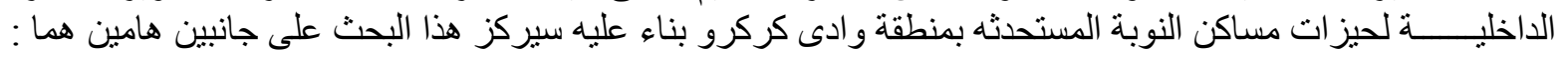

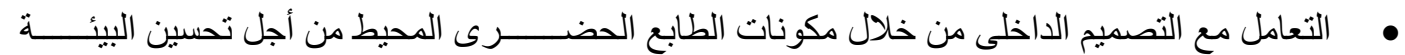

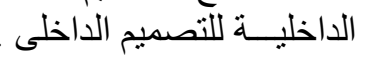

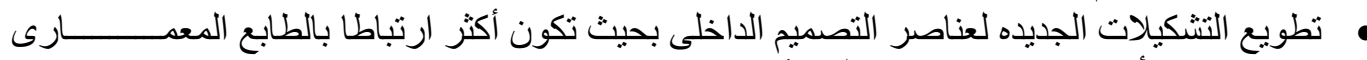

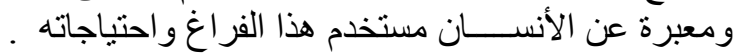




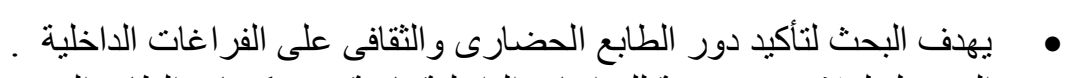

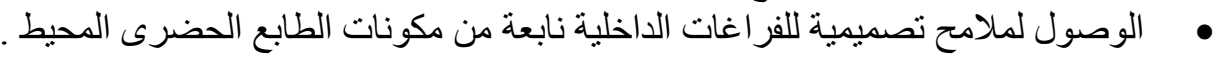

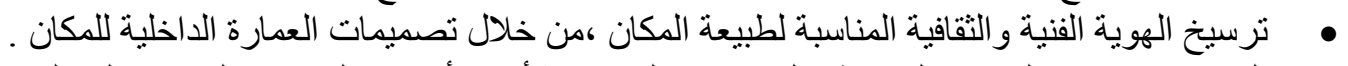

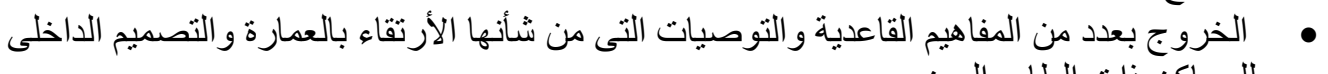

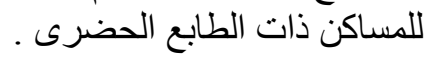

منهجية البحث

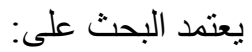

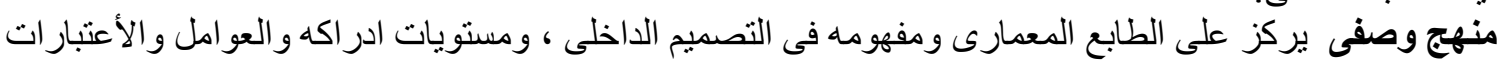
التصميمية المؤثره عليه

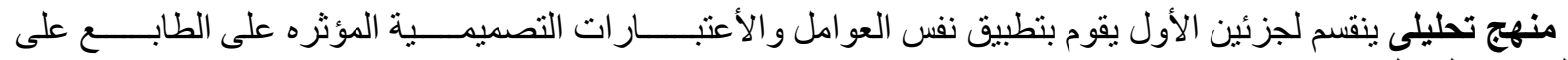

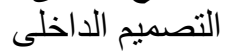
،و الجزء الثانى يقوم بمقارنة المنزل القديم بالمستحدث فى مفرداته المعمارية و عناصر عمارته الداخلية .

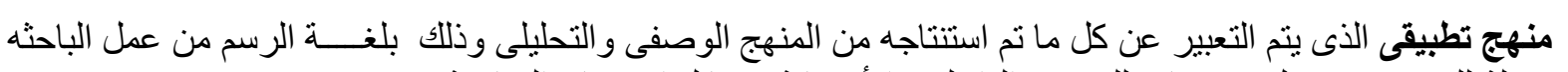

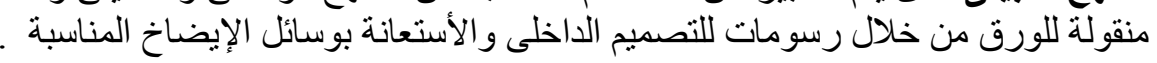

البحث

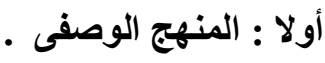 \\ تعريف مفهوم الطابع}

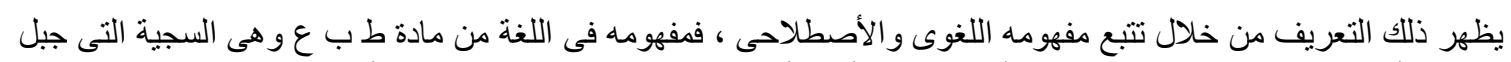

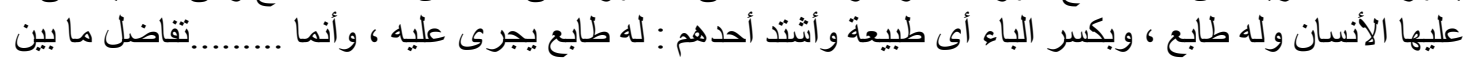

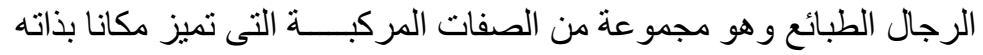

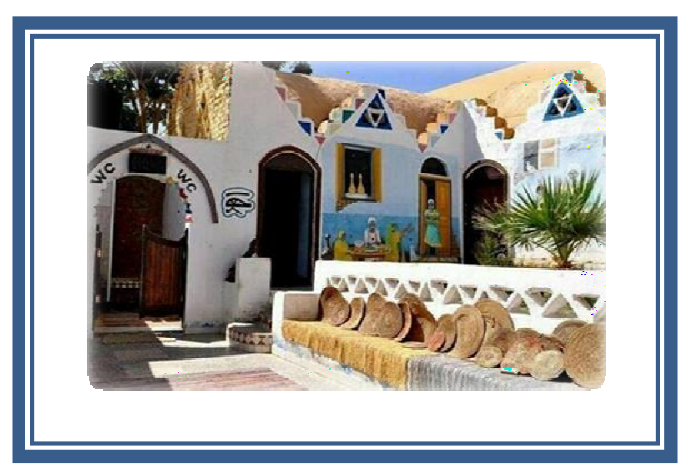

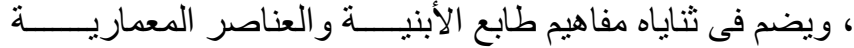

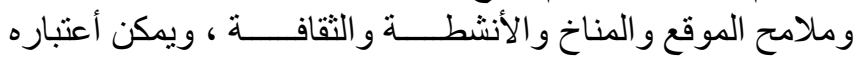

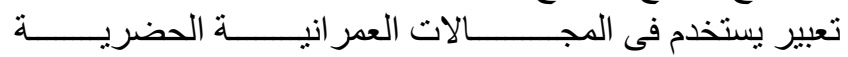

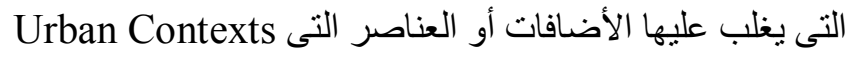

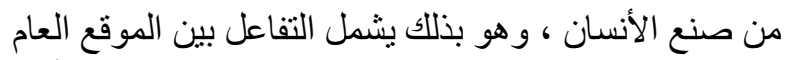

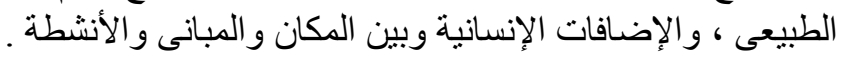

شكل (2 ) الطابع فى التصميم الداخلى للمسكن النوبى .

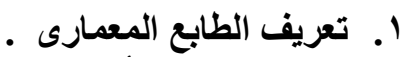

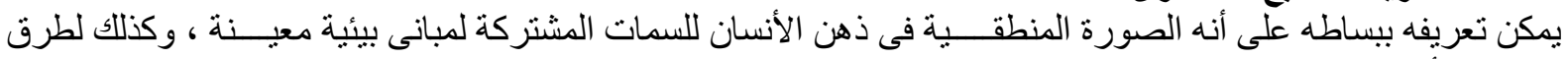

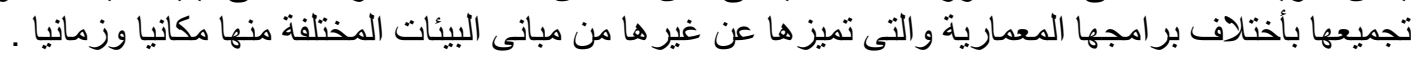

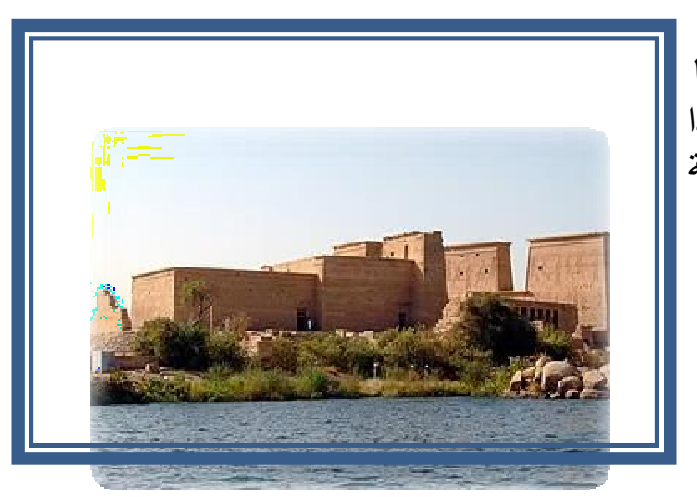

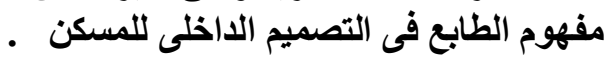

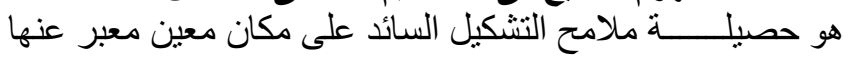

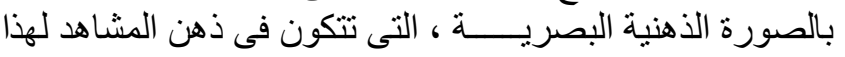

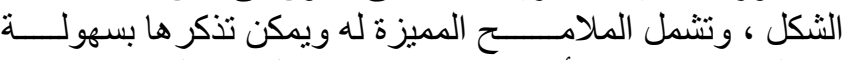

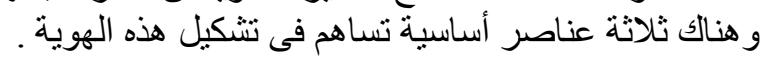

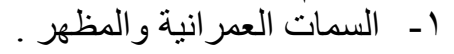
r r- الفعاليات و الوظائف السائدة .

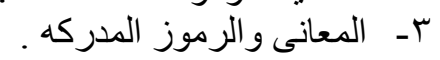

شكل (־ّ ) الطابع العام بمدينة أسوان . 


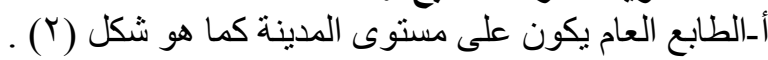

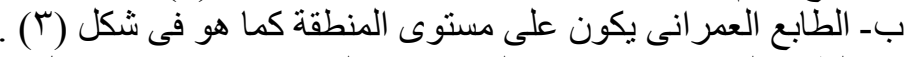

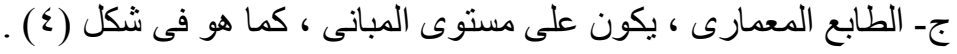

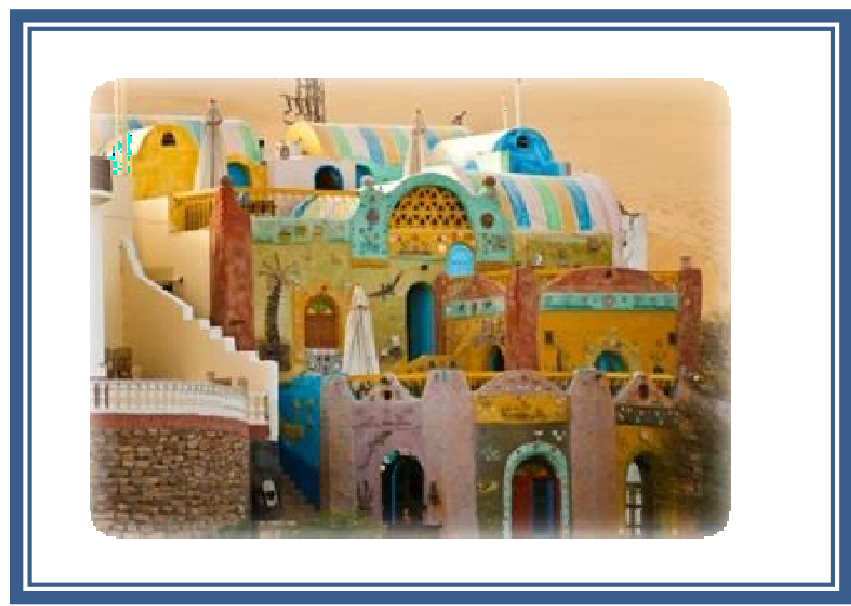

$$
\text { شكل (؛ ) الطابع المعمارى لمستوى المبانى . مان. }
$$

ويجدر الأشارة إلى أن يتم ملامح التشكيل السائدة فى مكان ما ،و المكونة لطابعه بحيث لا تعمل كل منها منفردة بل قيمة

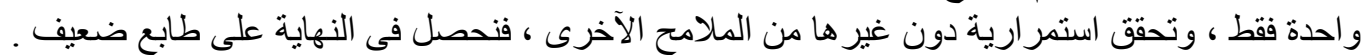

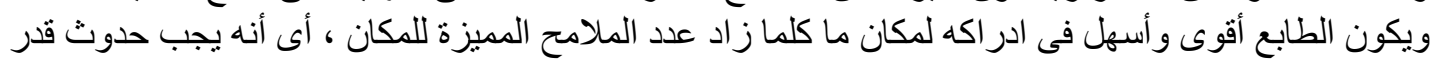

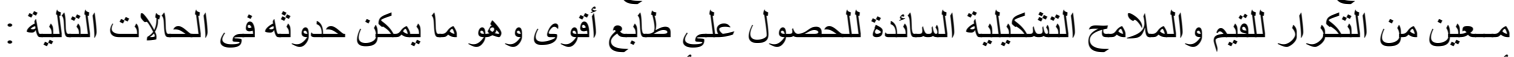

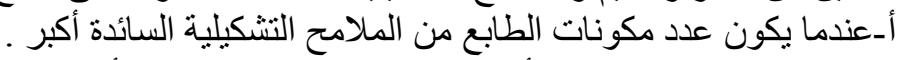

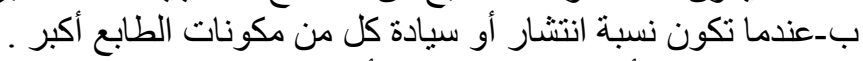

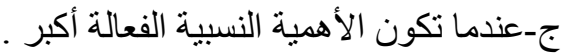

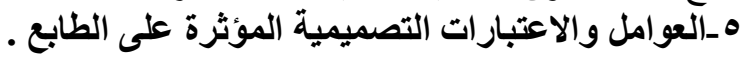

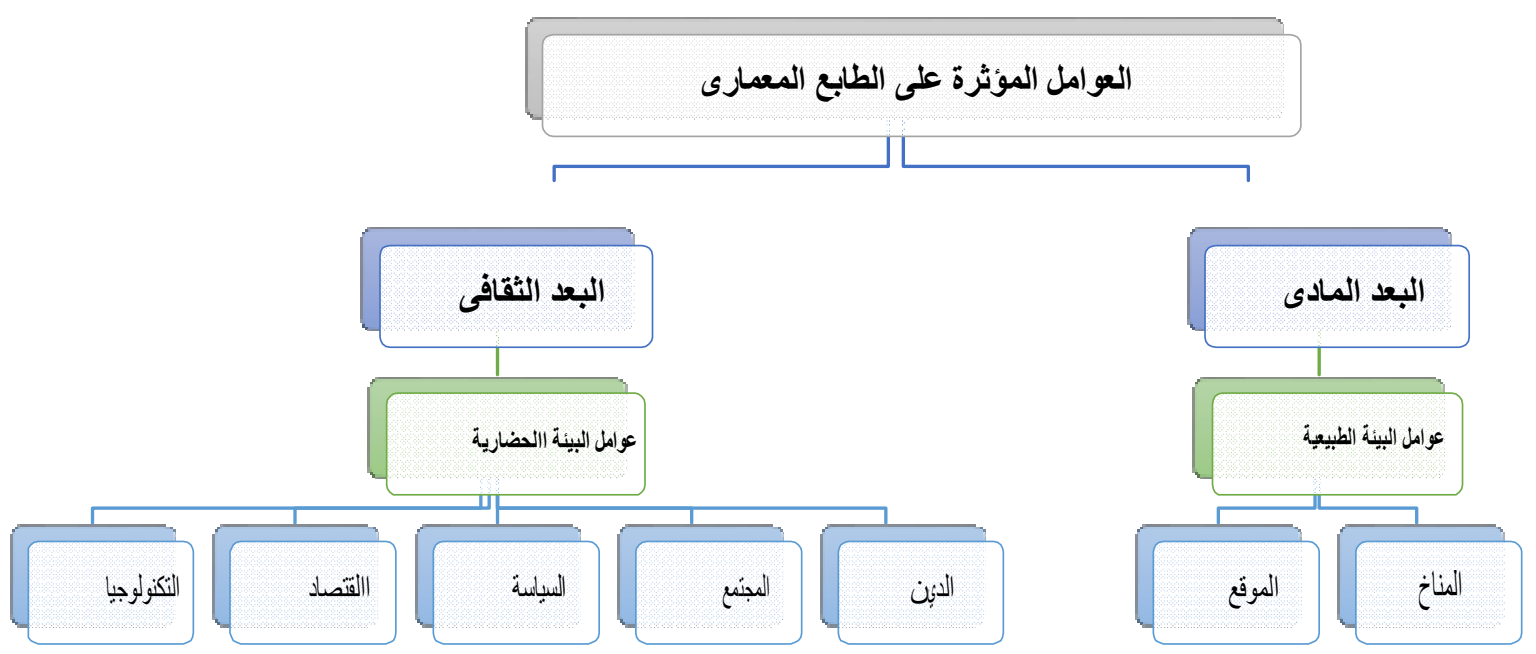

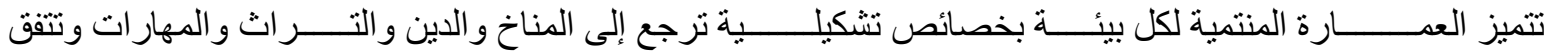

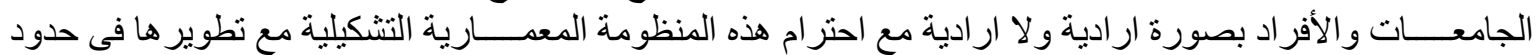

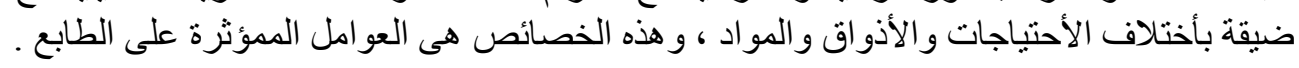


ه. 1.0

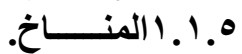

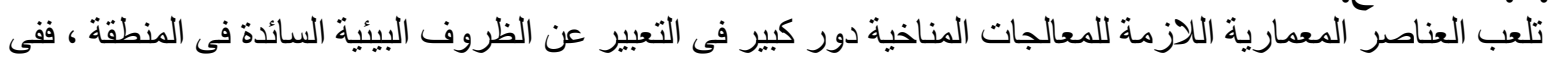

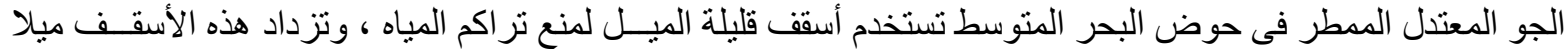

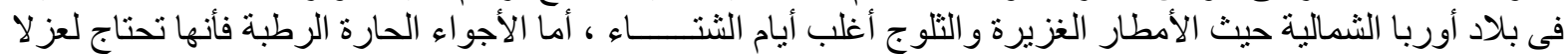

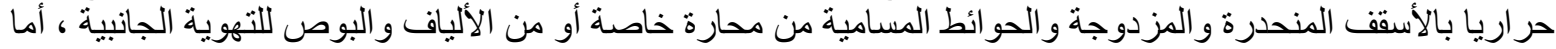

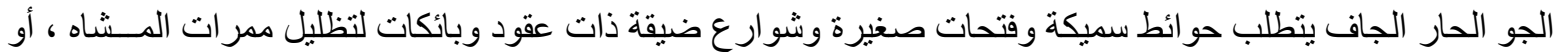

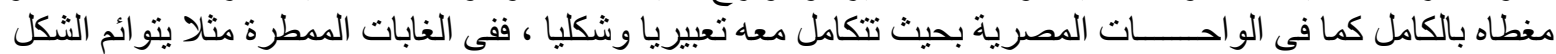

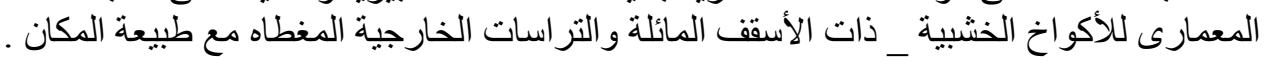

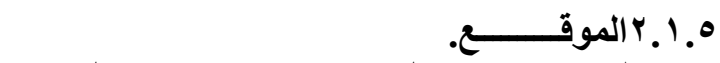

يتحدد الموقع بعدة عو امل كما هو موضح فى شكل (0) . التأثير الطبوغرافى بعد النيا

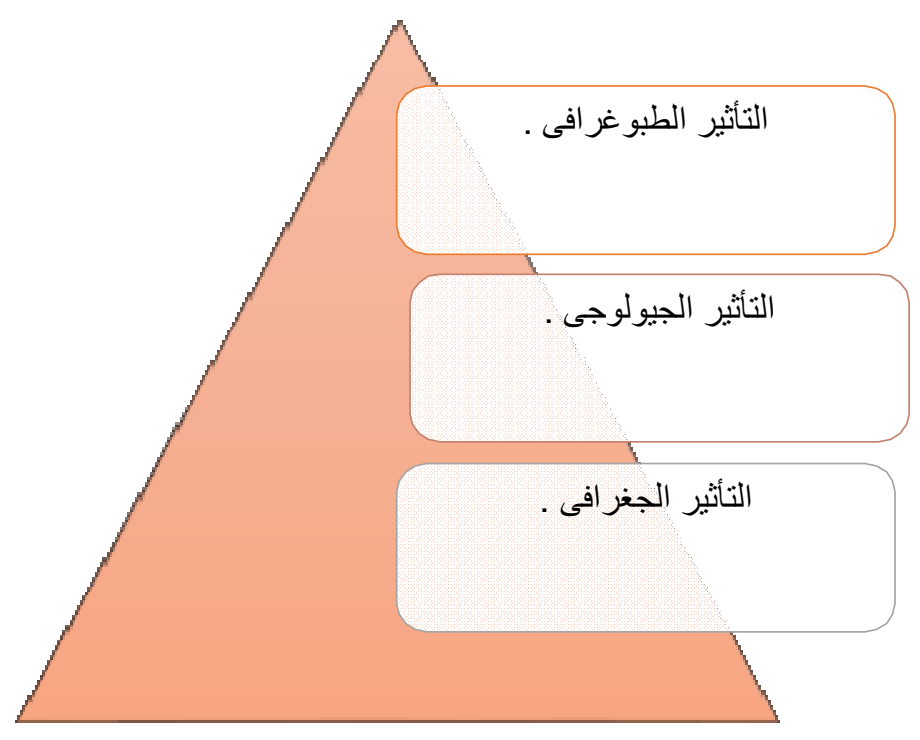

شكل (0) العوامل المؤثرة على الموقع .

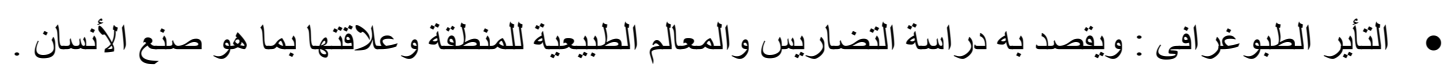

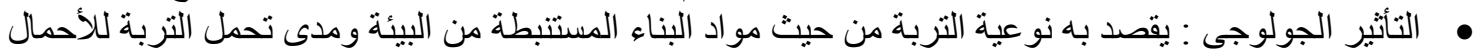
الو اقعة عليها . التولير

• التأثير الجغر افى : يقصد بها دراسة جغر افية المكان والبحار ،و الأنهار المحيطة كما هو فى شكل (†) .

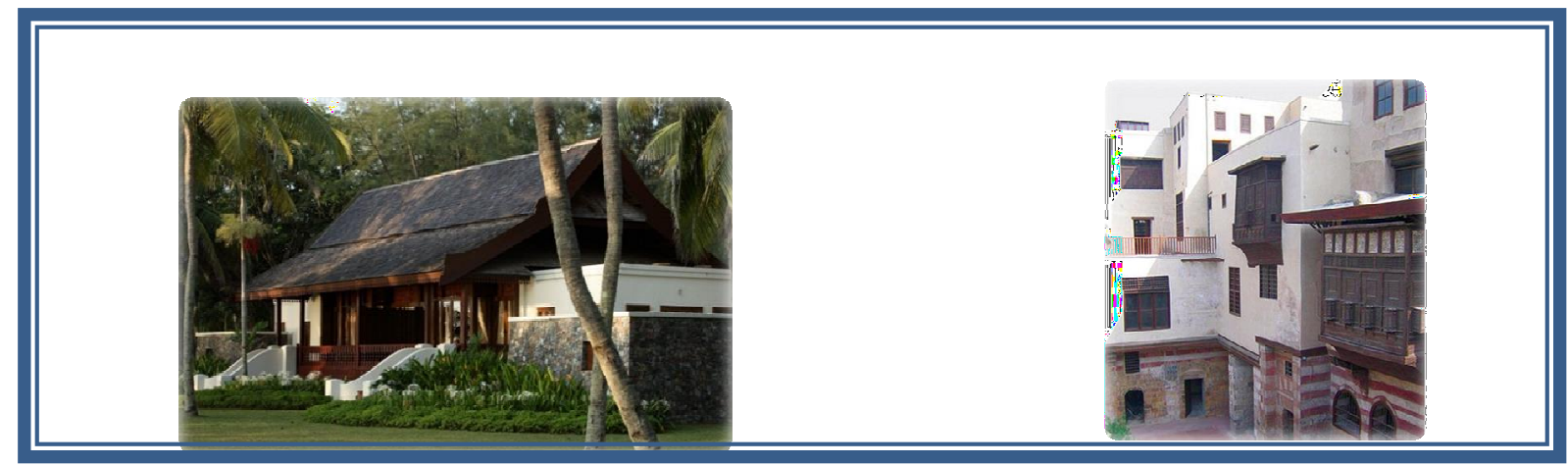

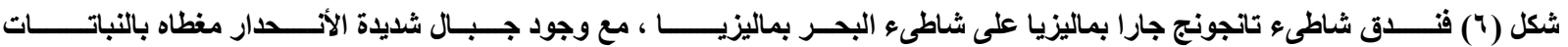

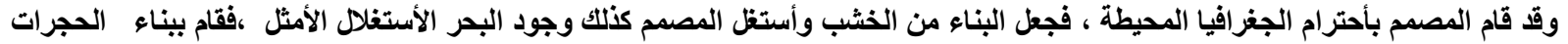

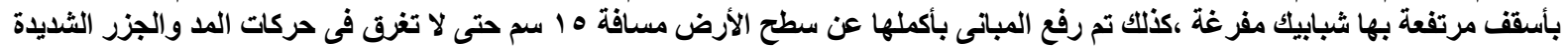




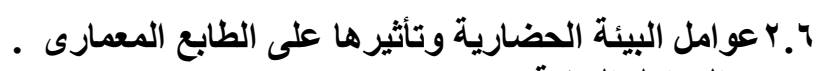

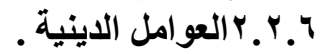

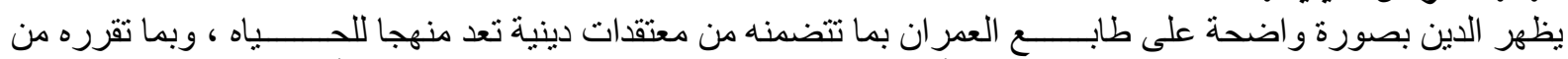

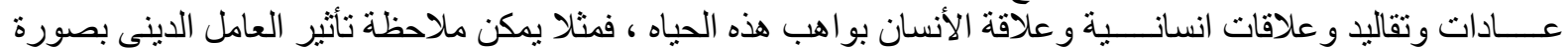

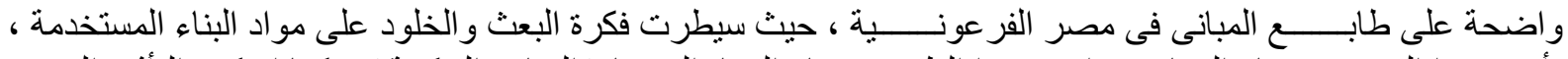

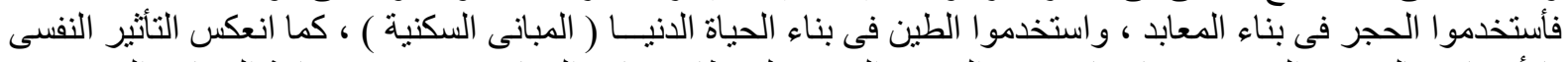

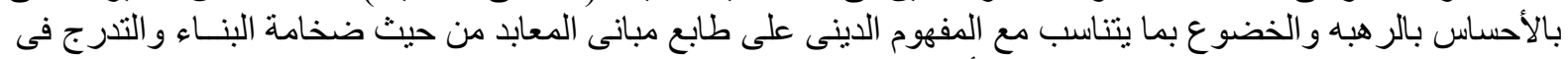

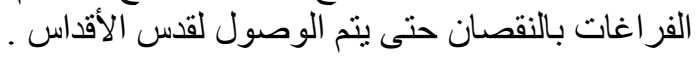

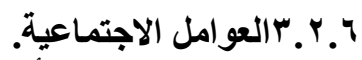

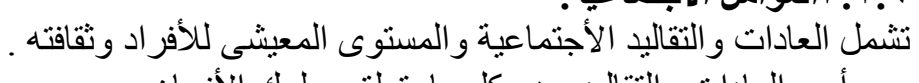

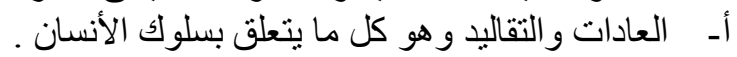

بـ العلاقات الأنسانية وتثمل مدى ارتباط سكان المنطقة بالأنشطة الجماعية المرتبطة بالمستوى الثقافـــى والمادى

$$
\text { تــ المستوى المعيشى ويتوقف على المستوى الثقافى و المادى ومدى الأنفتاح على البيئات المحيطة . }
$$

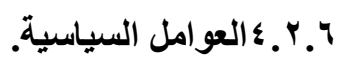

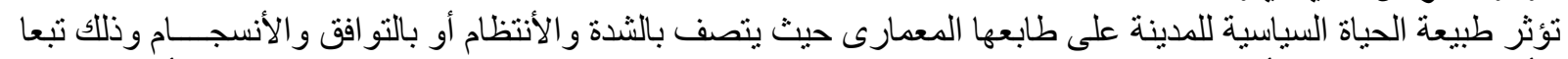

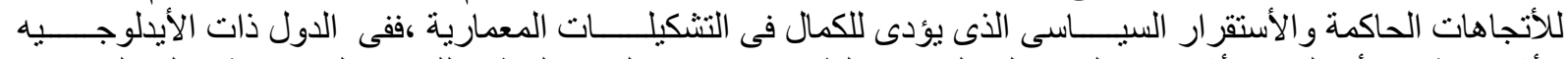

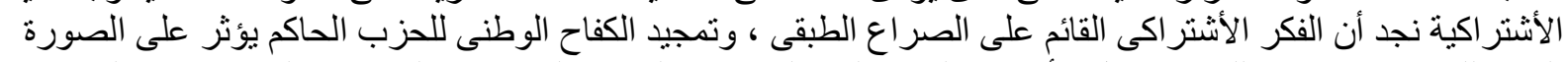

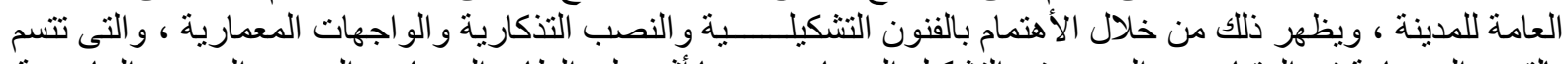

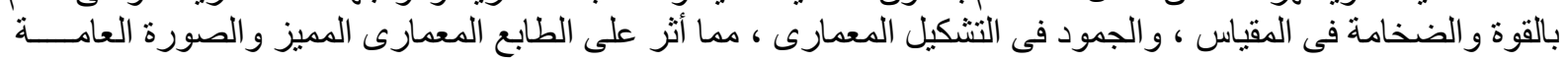
للمدينة .

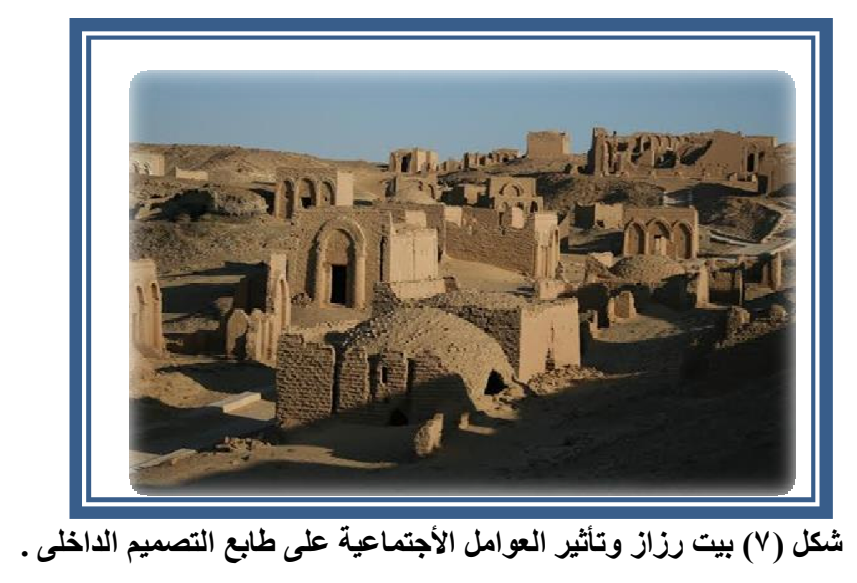

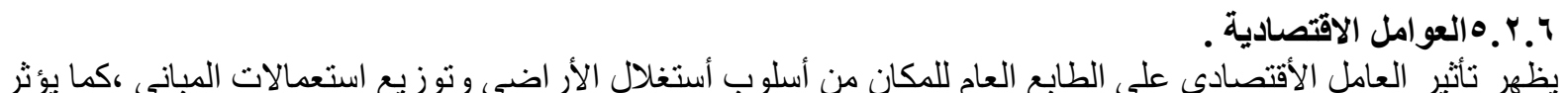

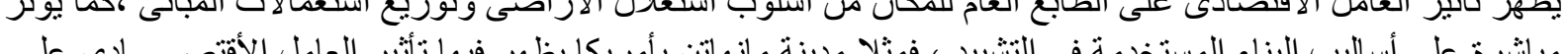

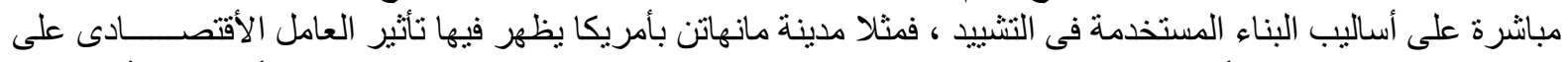

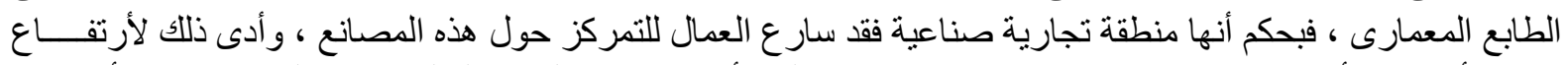

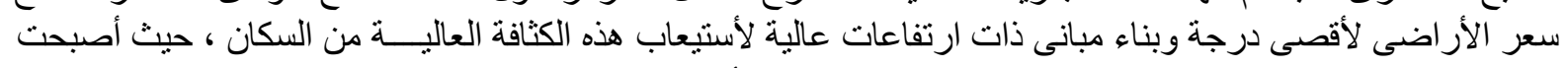

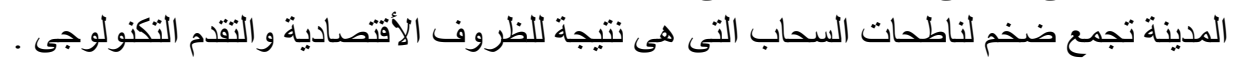




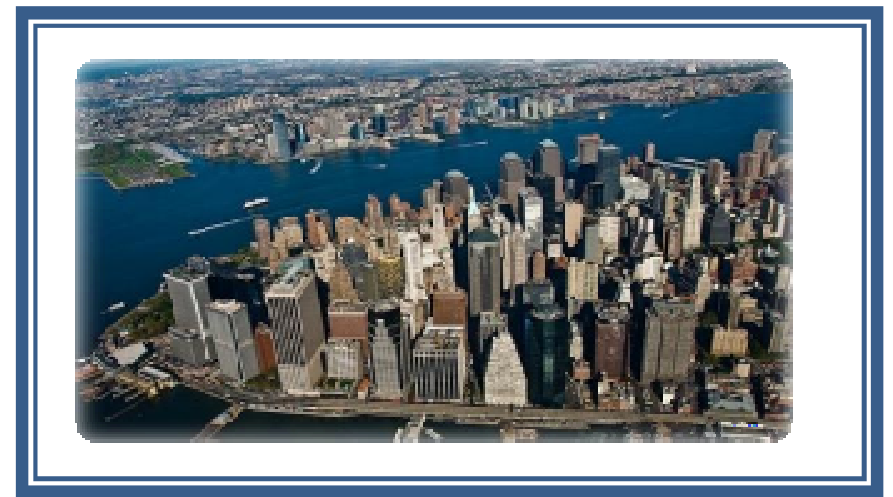

شكل (^) حى مانهاتن و هو أثهر الأحياء فى نيويورك فى الولايات المتحدة الأمريكية .

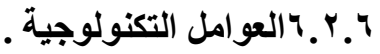

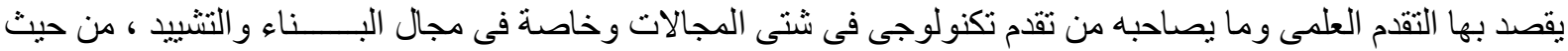

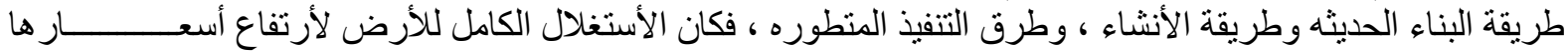

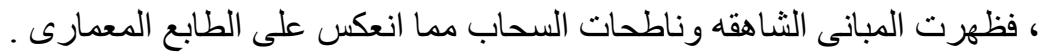

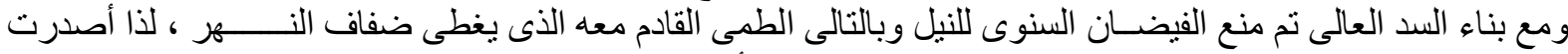

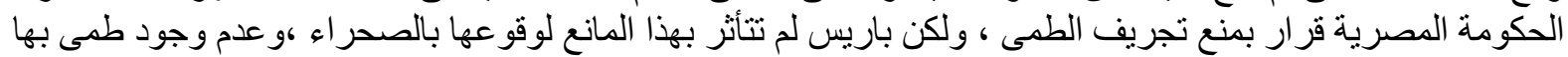

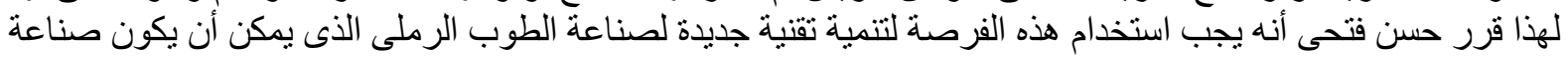
جديده بمصر وكان الطوب المستخدم فى باريز الجديده .

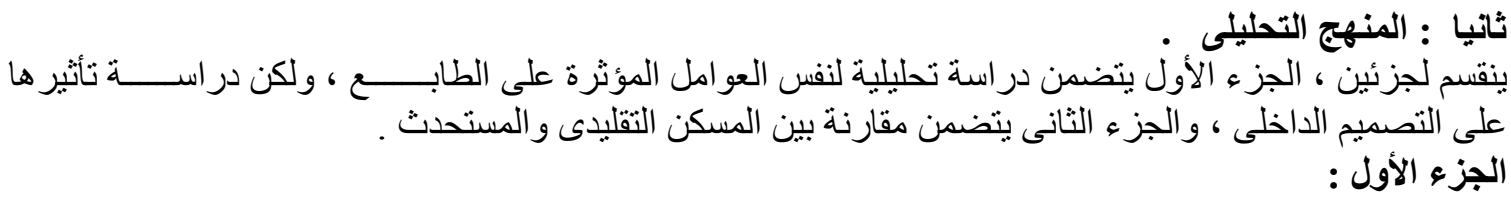




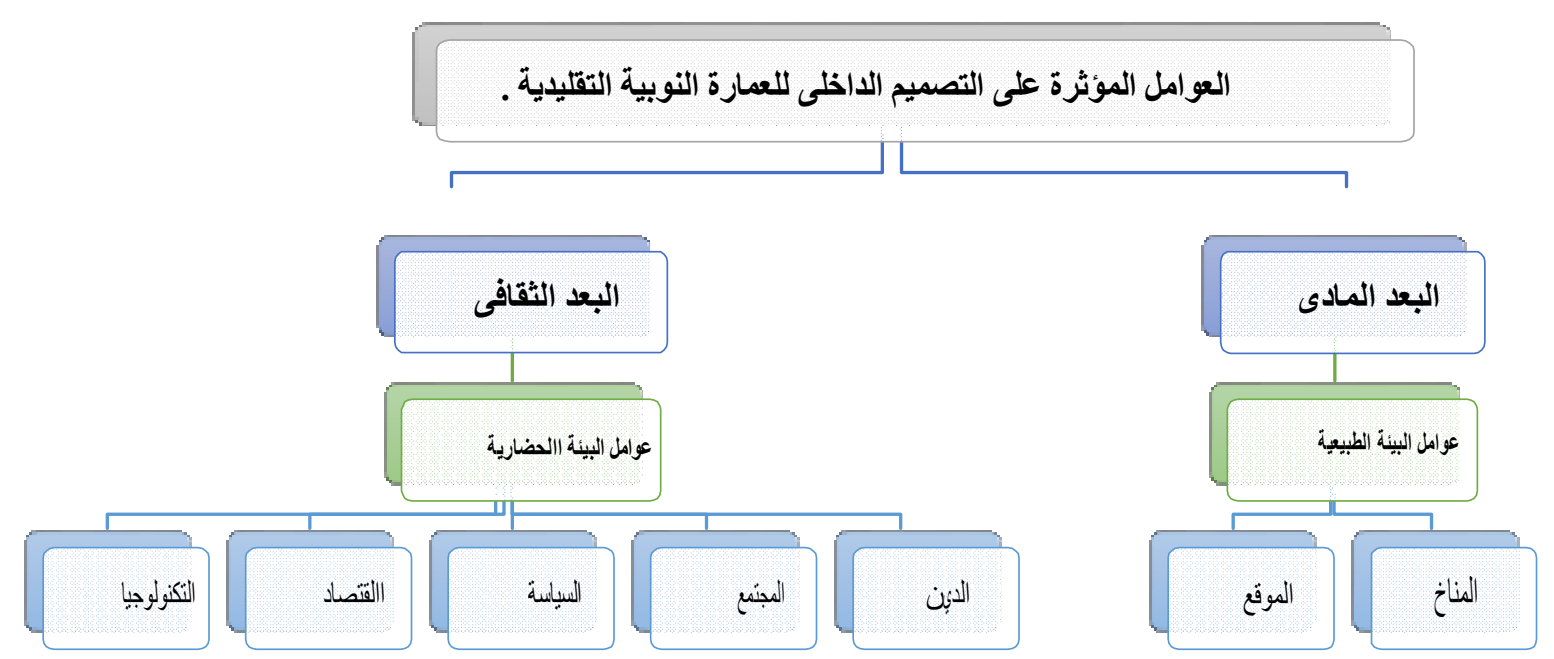

العوامل المؤثره على التصميم الداخلى للعمارة النوبية التقليدية .
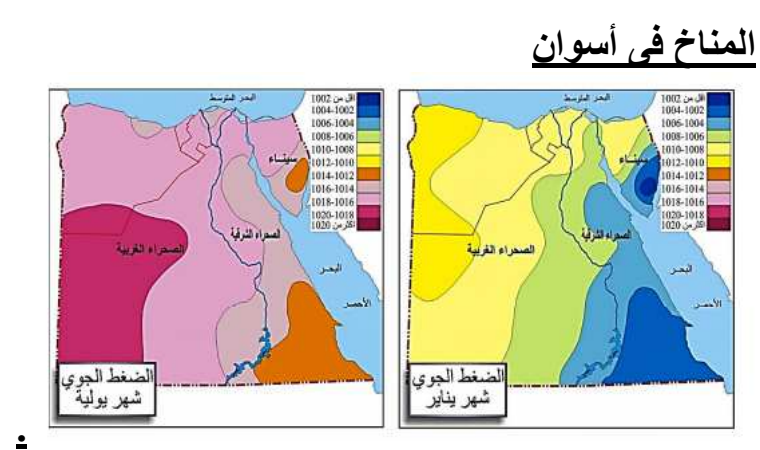

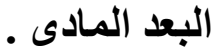

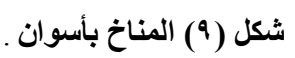

- مبسود أسوان نطاق من الضغط المنخفض قى شهر الثنتاء ل

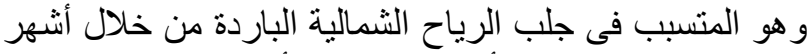

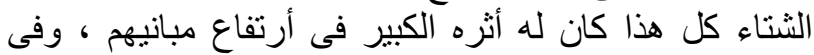

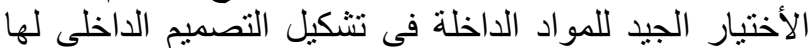
فمثلا تم الأستعانة بالأخثاب في الإلئ في المعالجات الداخلية للأسطح

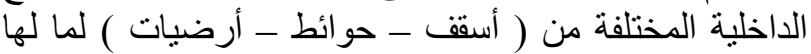

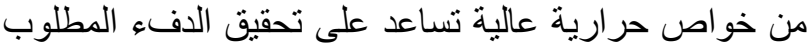

$$
\begin{aligned}
& \text { للفر اغ اغ أصن } \\
& \text { أما فى الصيف : }
\end{aligned}
$$

ـ تطعيم النو افذ بزجـــــاج عـــــــاكس للحر ارة ، و الأتجاه لتكبير

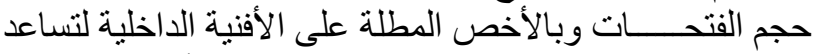

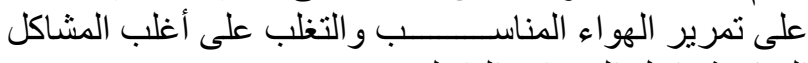
المناخية داخل الحيز ات الداء الذانيه .

ـأثر المناخ على التصميم الداخلى لمساكن النوبة القديمة ، حيث

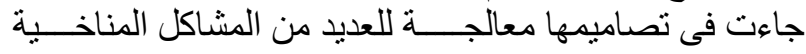

المناخ وتأثيره على التصميم الداخلى 


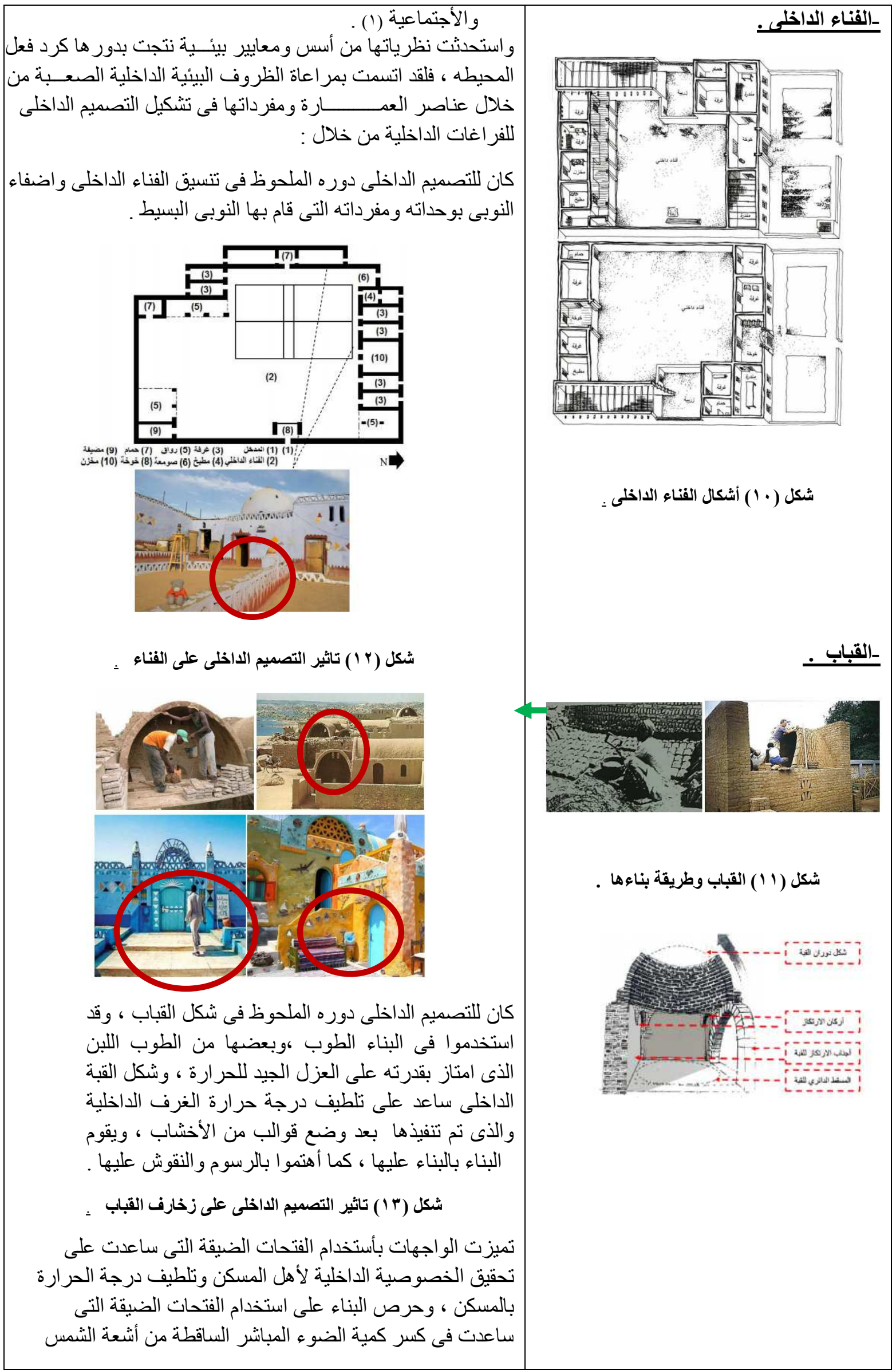




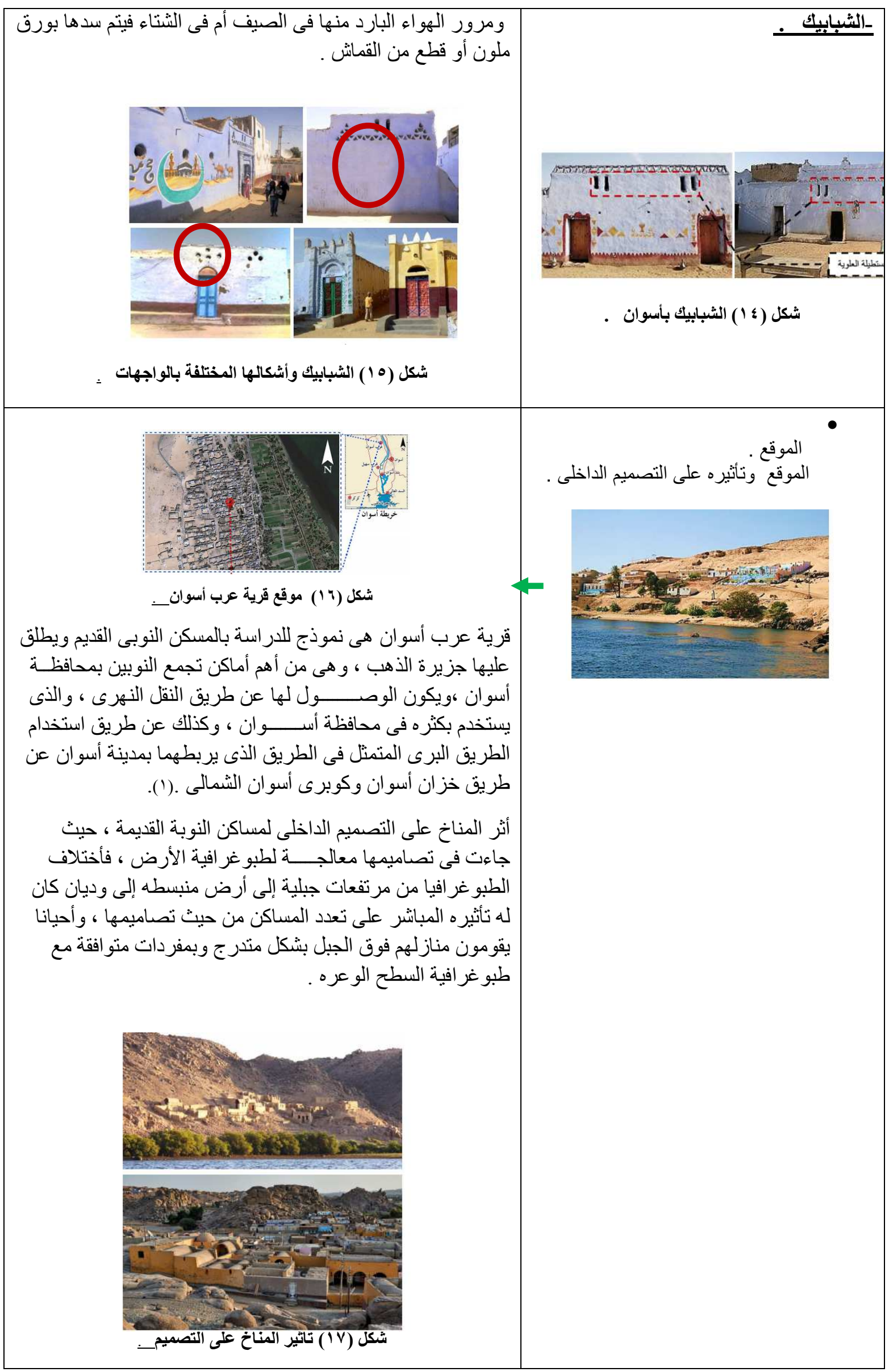




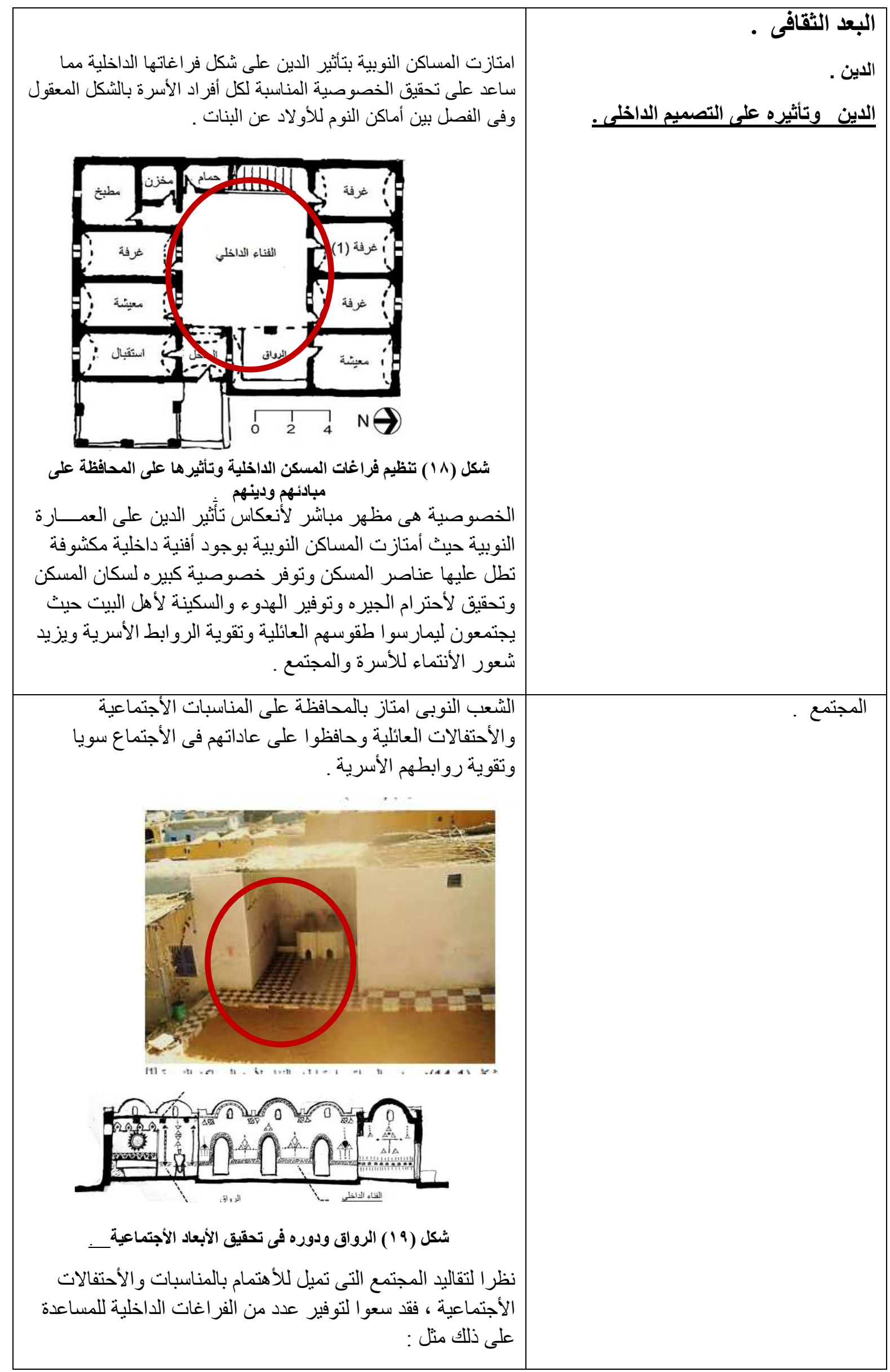




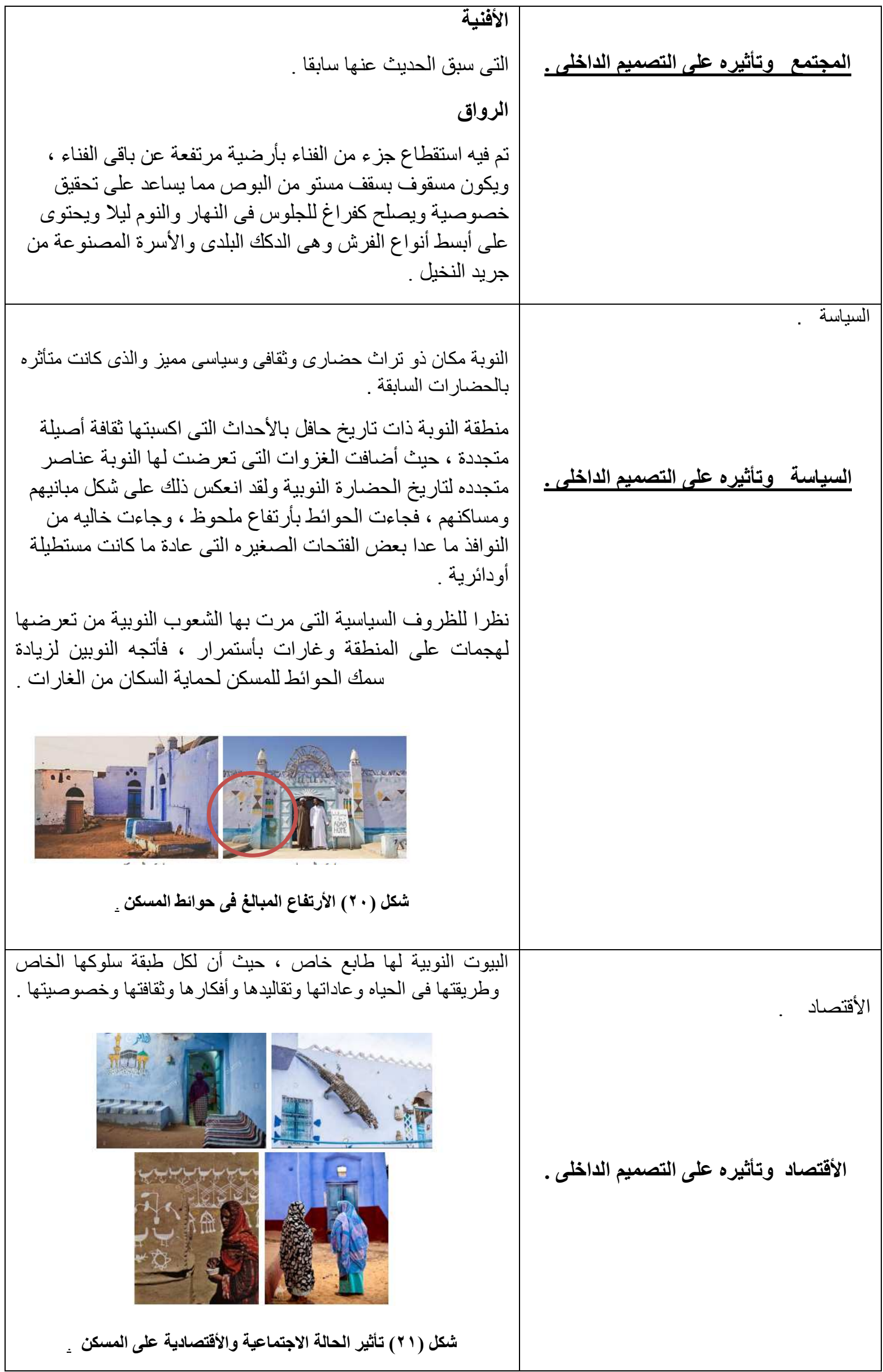




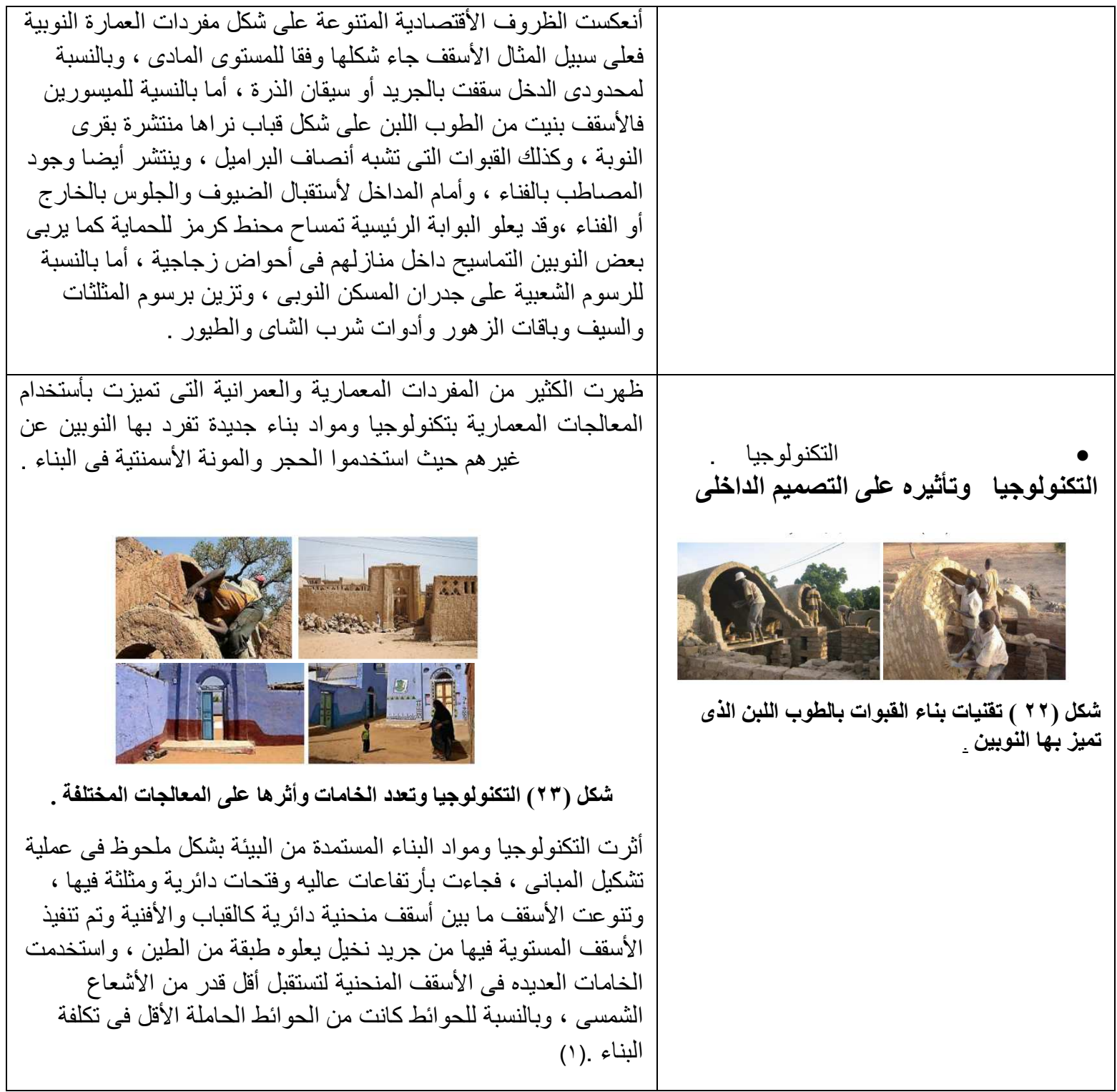

الجزء الثانى :

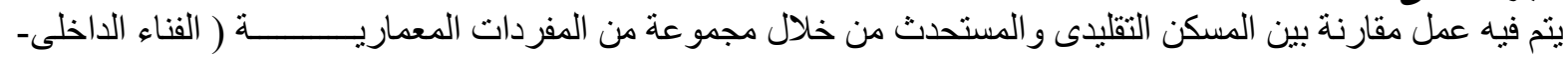

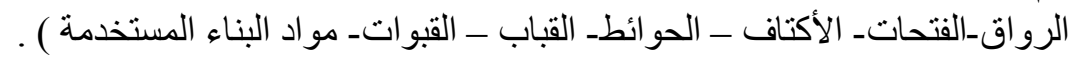




\begin{tabular}{|c|c|c|}
\hline المسكن المستحدث & المسكن التقليدى & المفرد \\
\hline 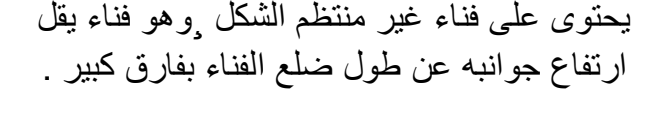 & 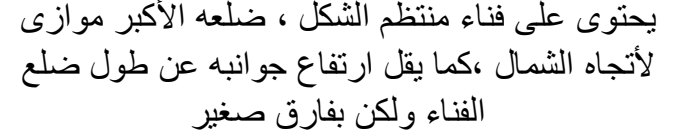 & \\
\hline 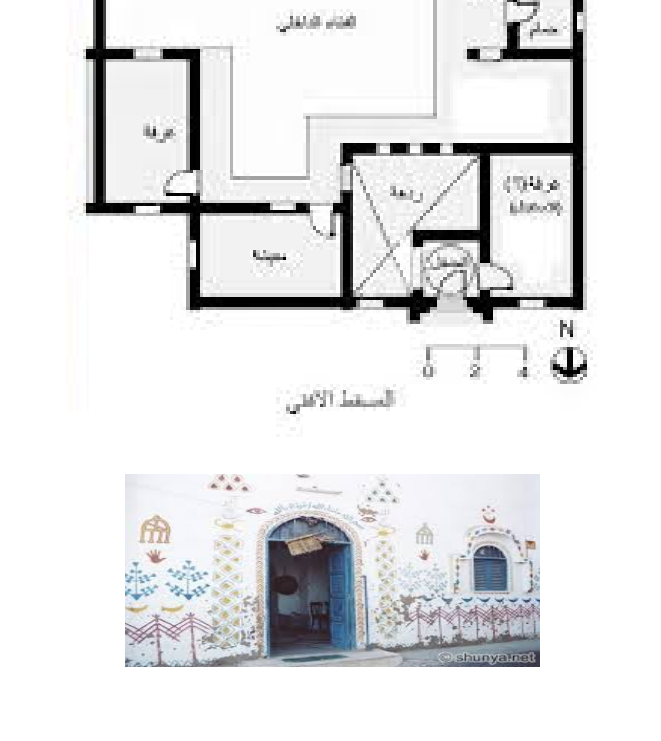 & & $\begin{array}{l}\overline{9} \\
\bar{a} \\
\bar{y} \\
\bar{y}\end{array}$ \\
\hline تلغطية لأحد أجز اء الجانبية للفناء فى الأتجاه الثنرقى خلال & 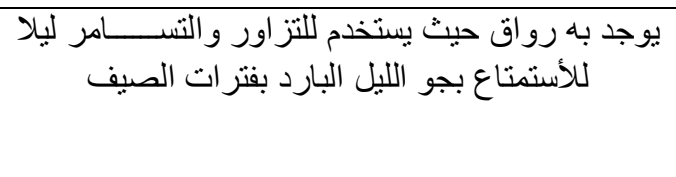 & $\overline{3}$ \\
\hline 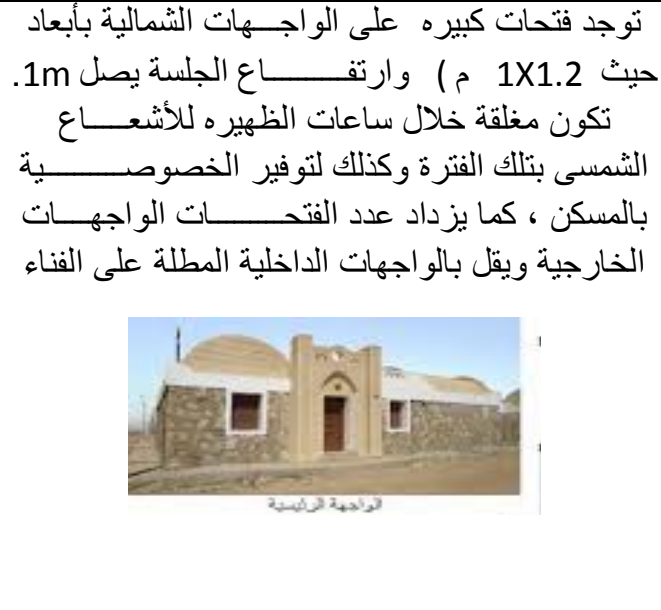 & 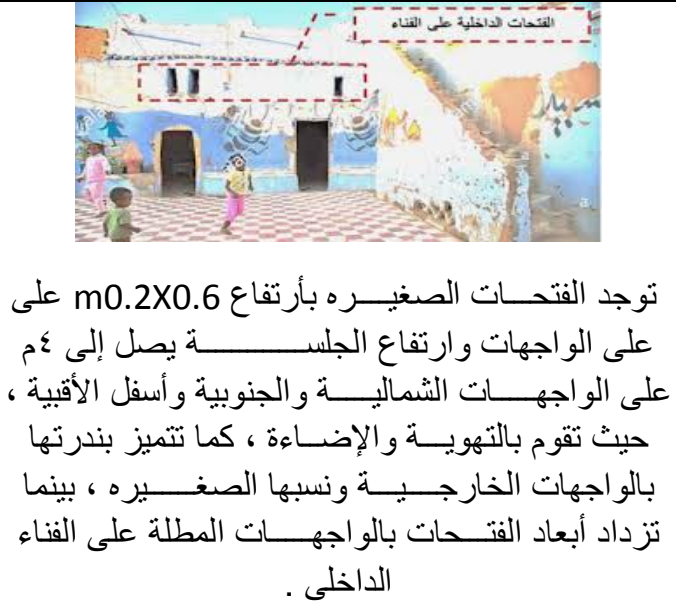 & 河 \\
\hline
\end{tabular}


إيجاد علاقة تر ابطية بين التصميم الداخلى و الطابع الحضرى .

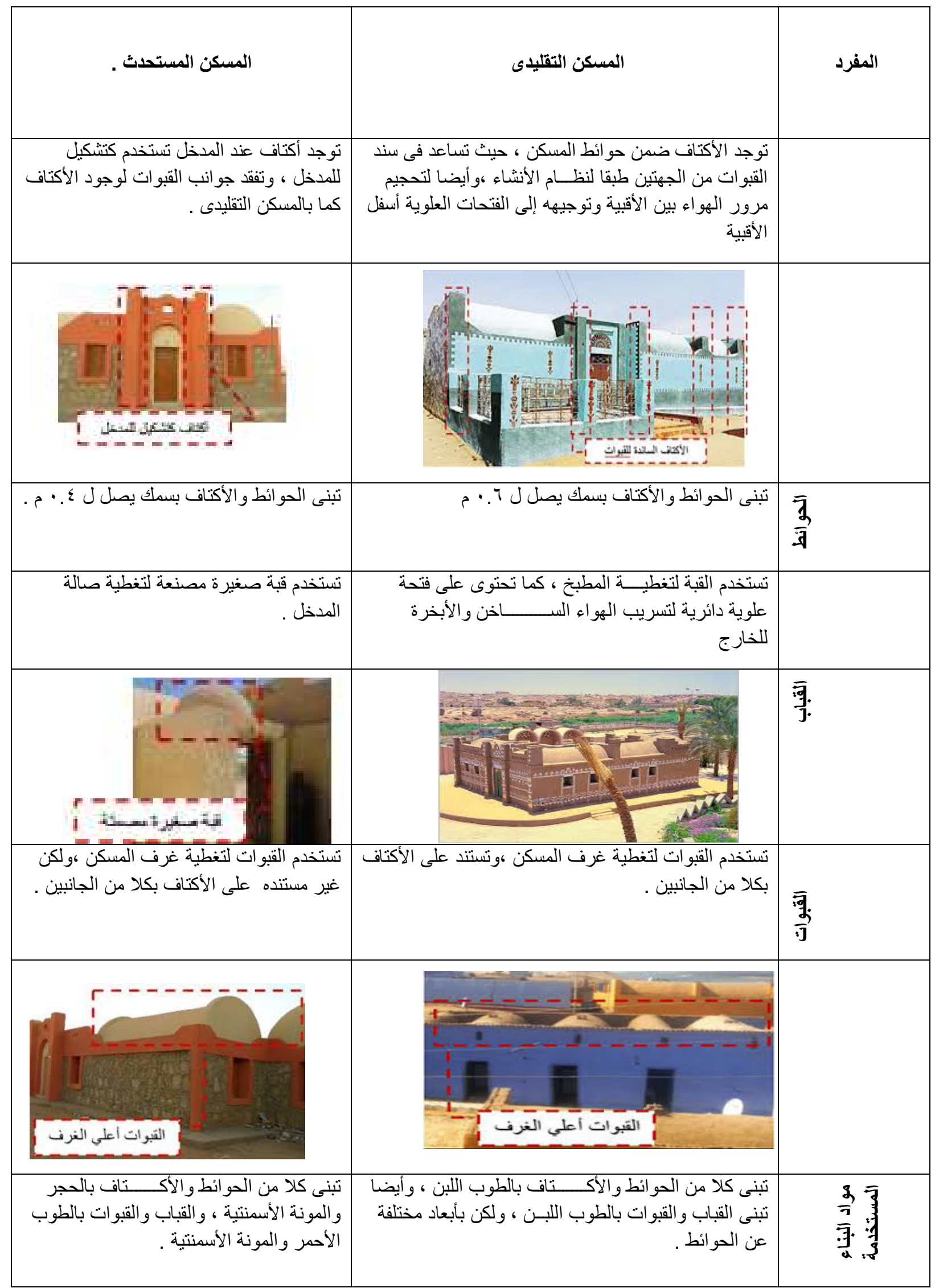




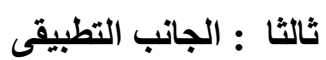

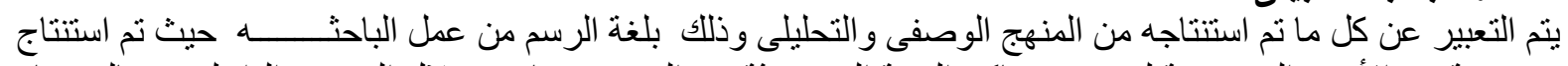

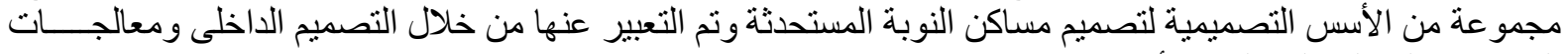
الفضاءات الداخلية المختلفة كالأتى :

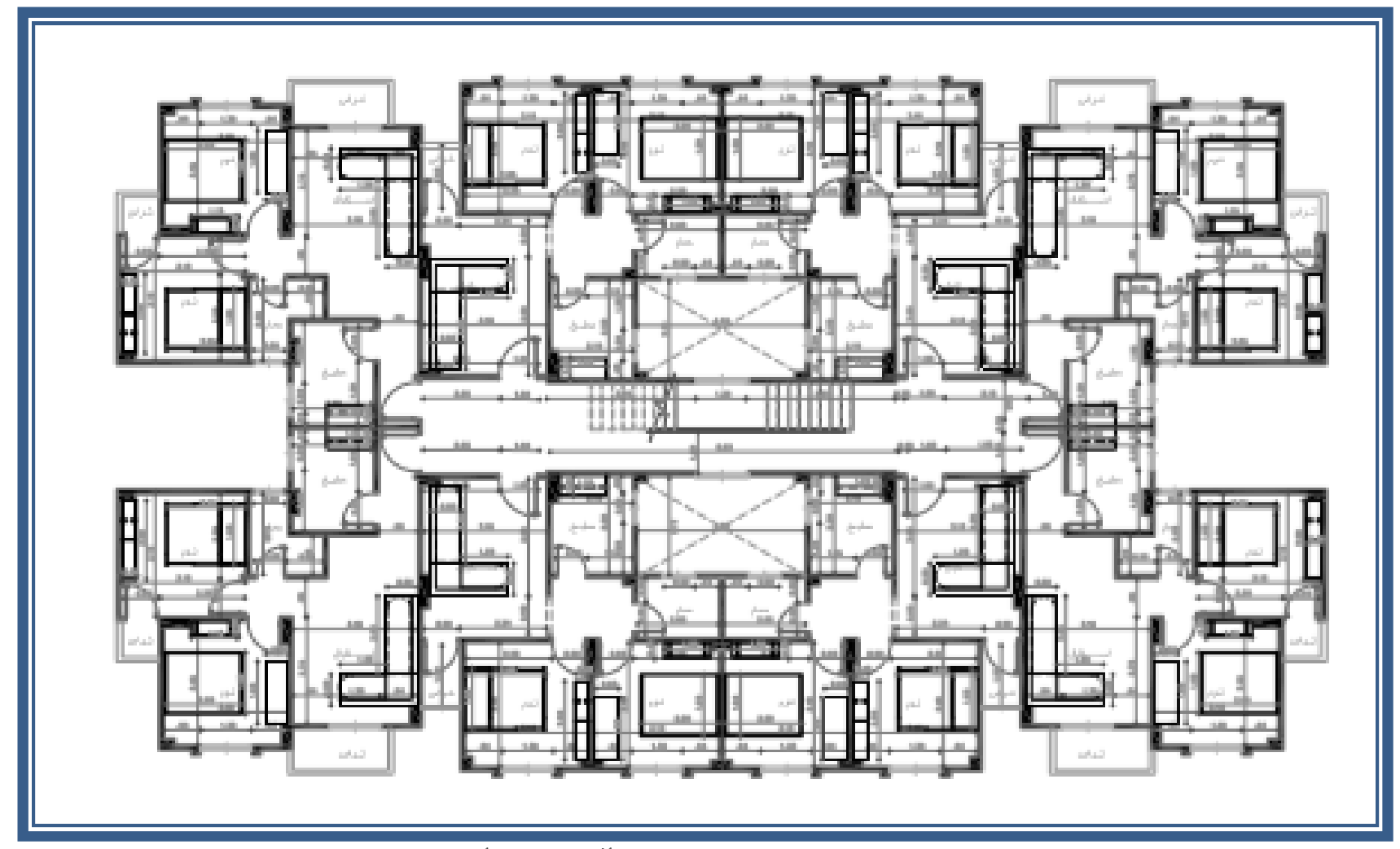

شكل (§ ץ) المسقط الأفقى لمسكن بأسوان .

الحلول التصميمية المقترحة لمعالجة المسقط الأفقى ـ

- مقترح الأول

1 - - معالجات التصميم الداخلى للمسقط الأفقى.

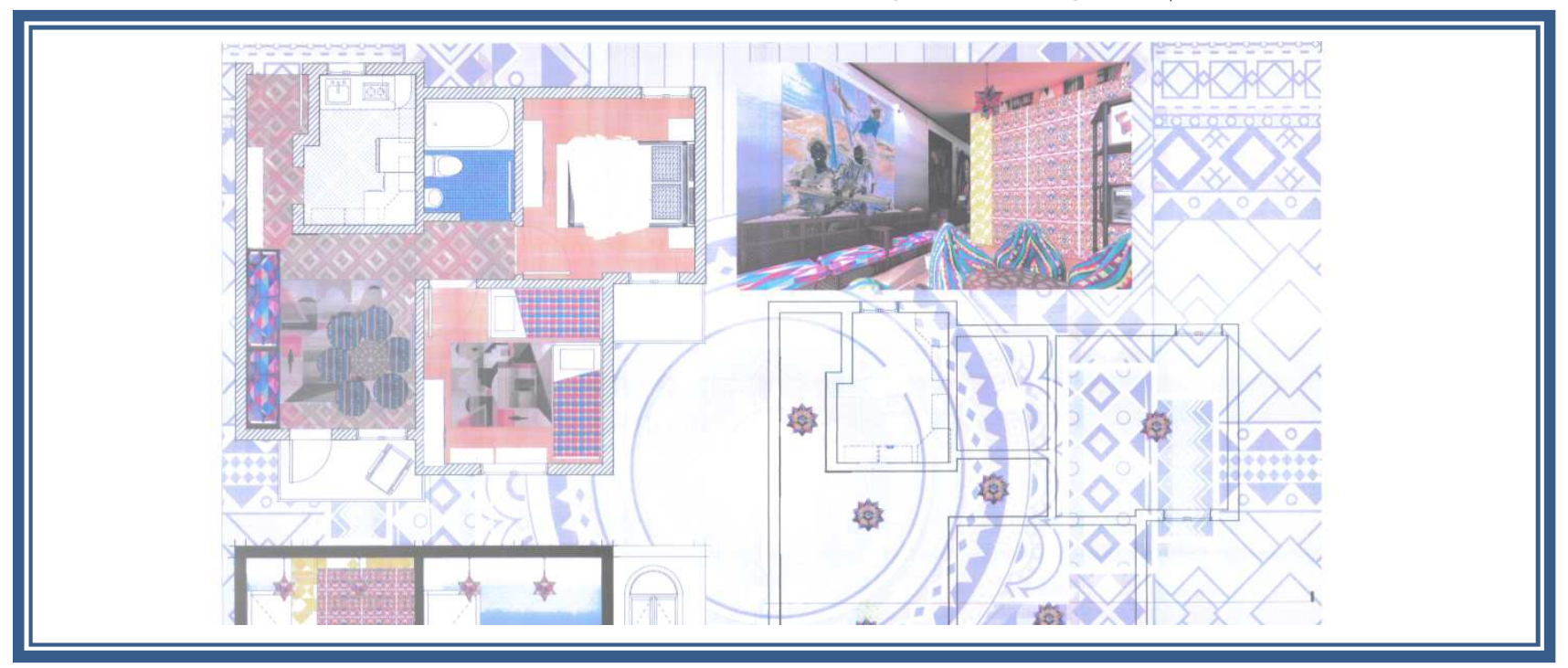

شكل (Y) معالجات التصميم الداخلى للمسقط الأفقى ( من عمل الباحثه ). 
r-معالجات التصميم الداخلى للأسقف الداخلية .

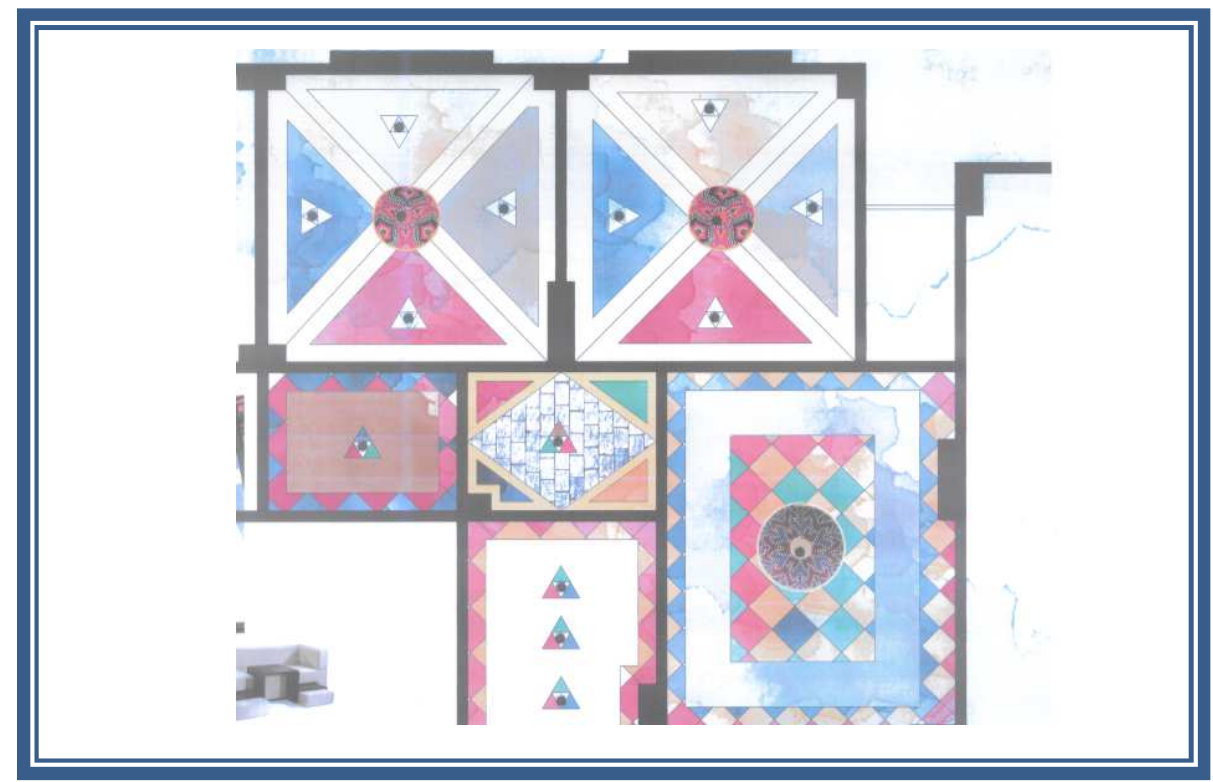

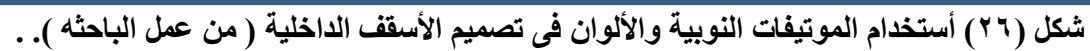

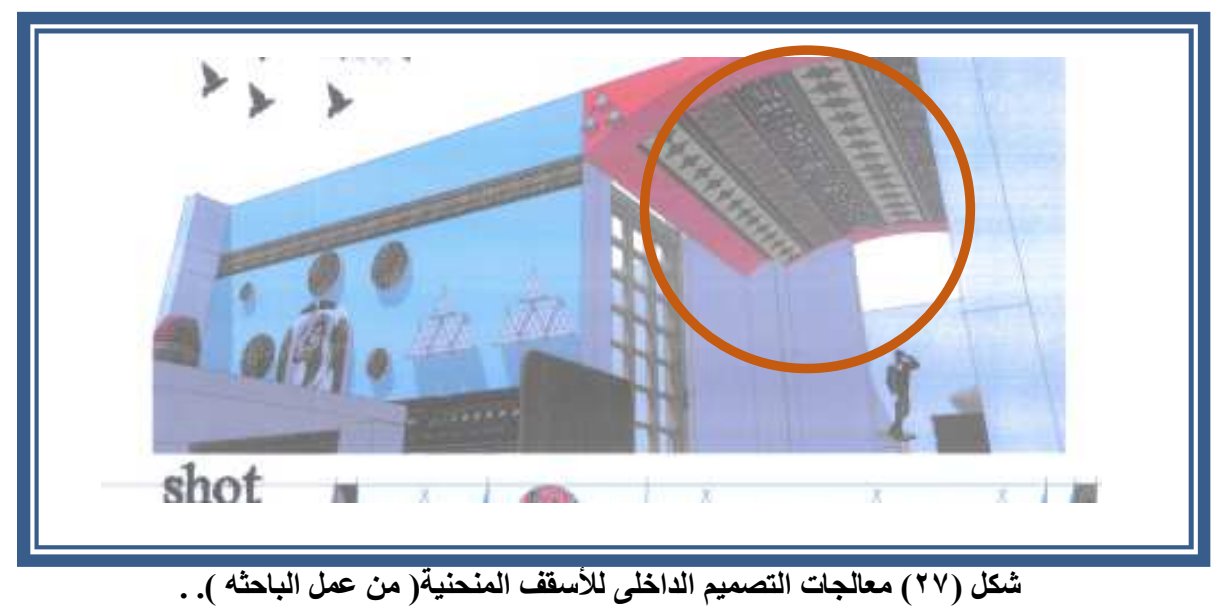

ب-معالجات التصميم الاخلى للحوائط الداخلية.

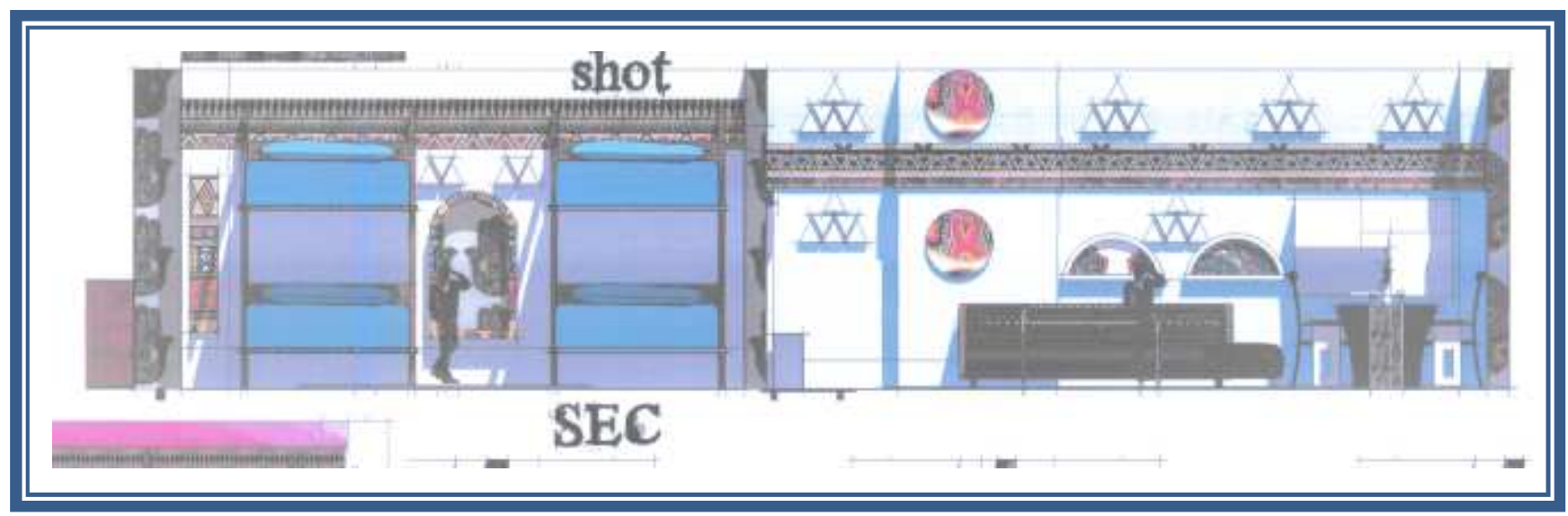

شكل (Y) (Y) معالجات التصميم الاخلى للقطاعات الداخلية ( من عمل الباحثه ).. 
إيجاد علاقة تر ابطية بين التصميم الداخلى و الطابع الحضرى ـ.

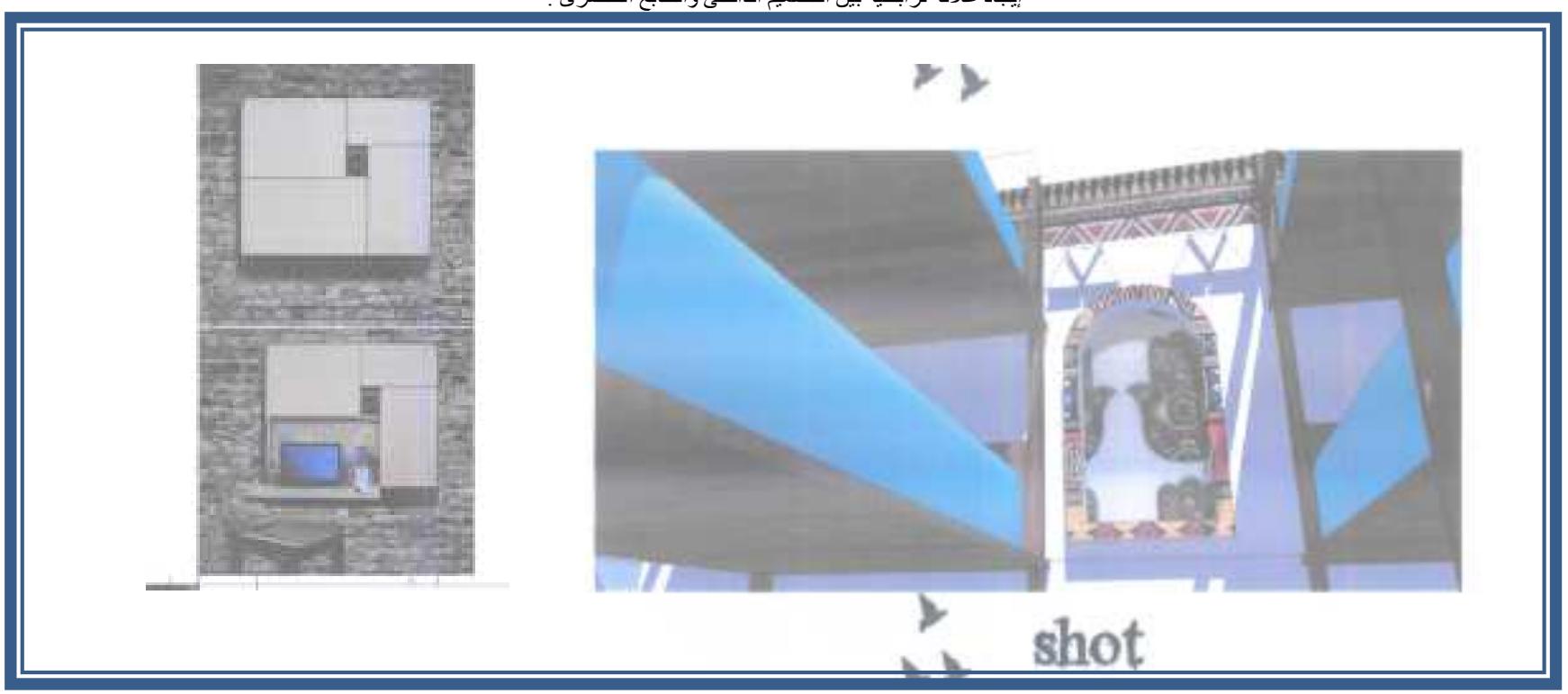

شكل (9 ץ) استخدام الزخارف الثعبية فى تزيين الجدران الاخلية ( من عمل الباحثه )..

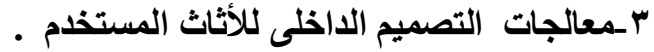

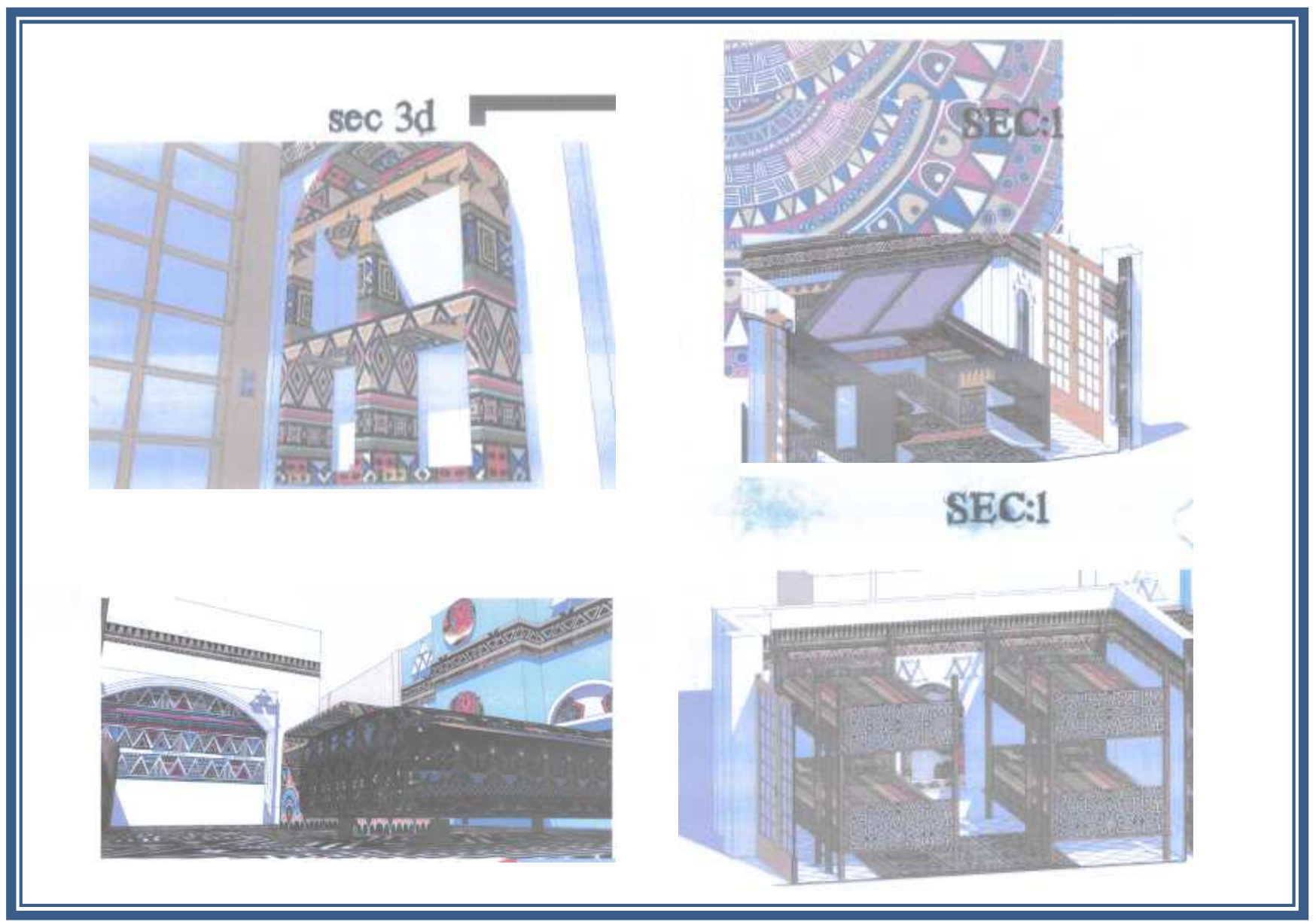

شكل (· • أشكال المعالجات المختلفة للفراغات الاخلية ( من عمل الباحثه ).. 
إيجاد علاقة تر ابطية بين التصميم الداخلى و الطابع الحضرى ـ.

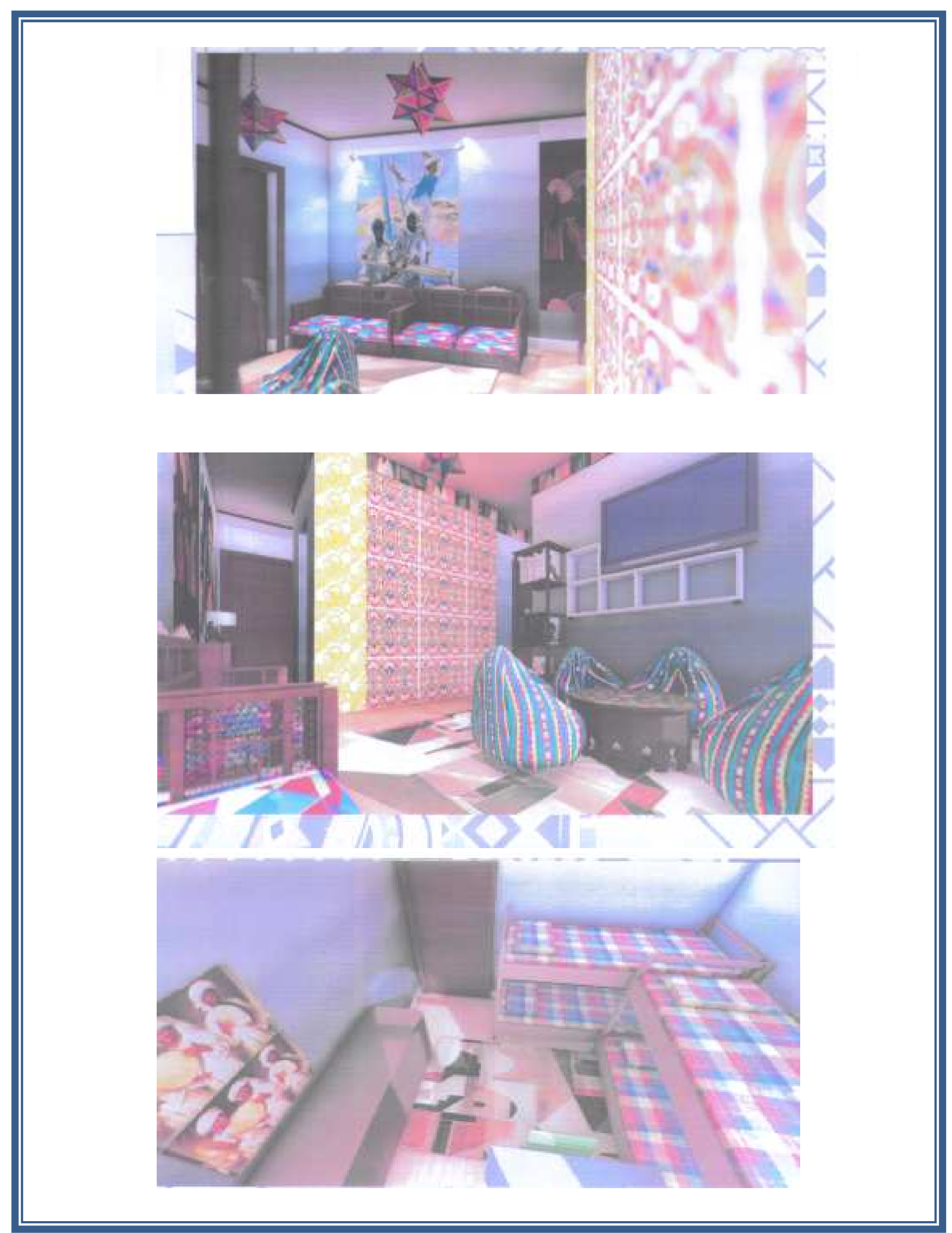

شكل ( آس) أستخذام التصميم الداخلى لتحقيق الأحتياجات المستقبلية للأسرة ( من عمل الباحثه ). 


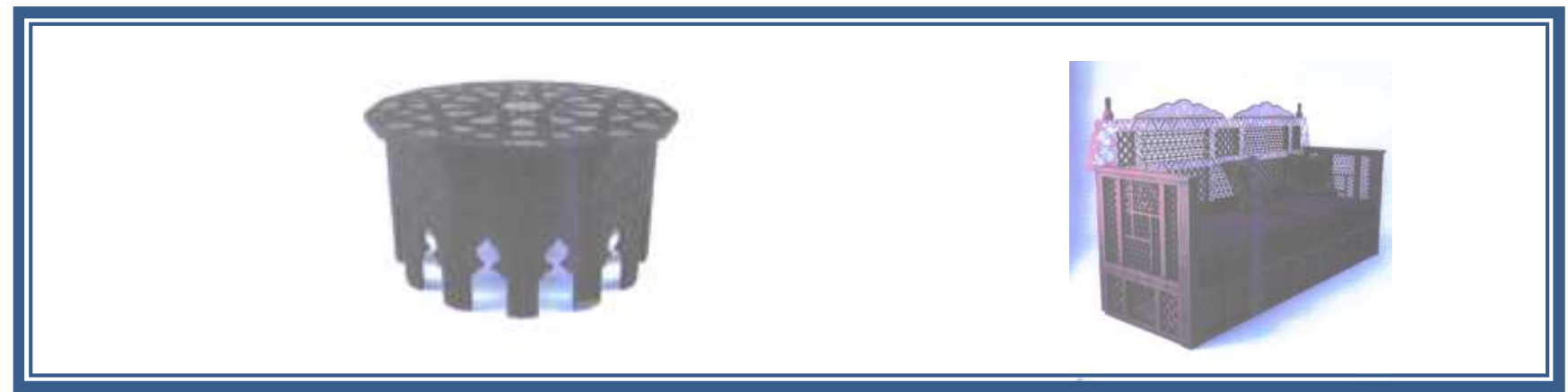

شكل (rr) أستخدام التصميم الأخلى لتحقيق الأحتياجات المستقبلية للأسرة فى تصميم الأثاث المستخدم ( من عمل الباحثه ). .

ب-معالجات التصميم الداخلى لمكملات التصميم الداخلى .

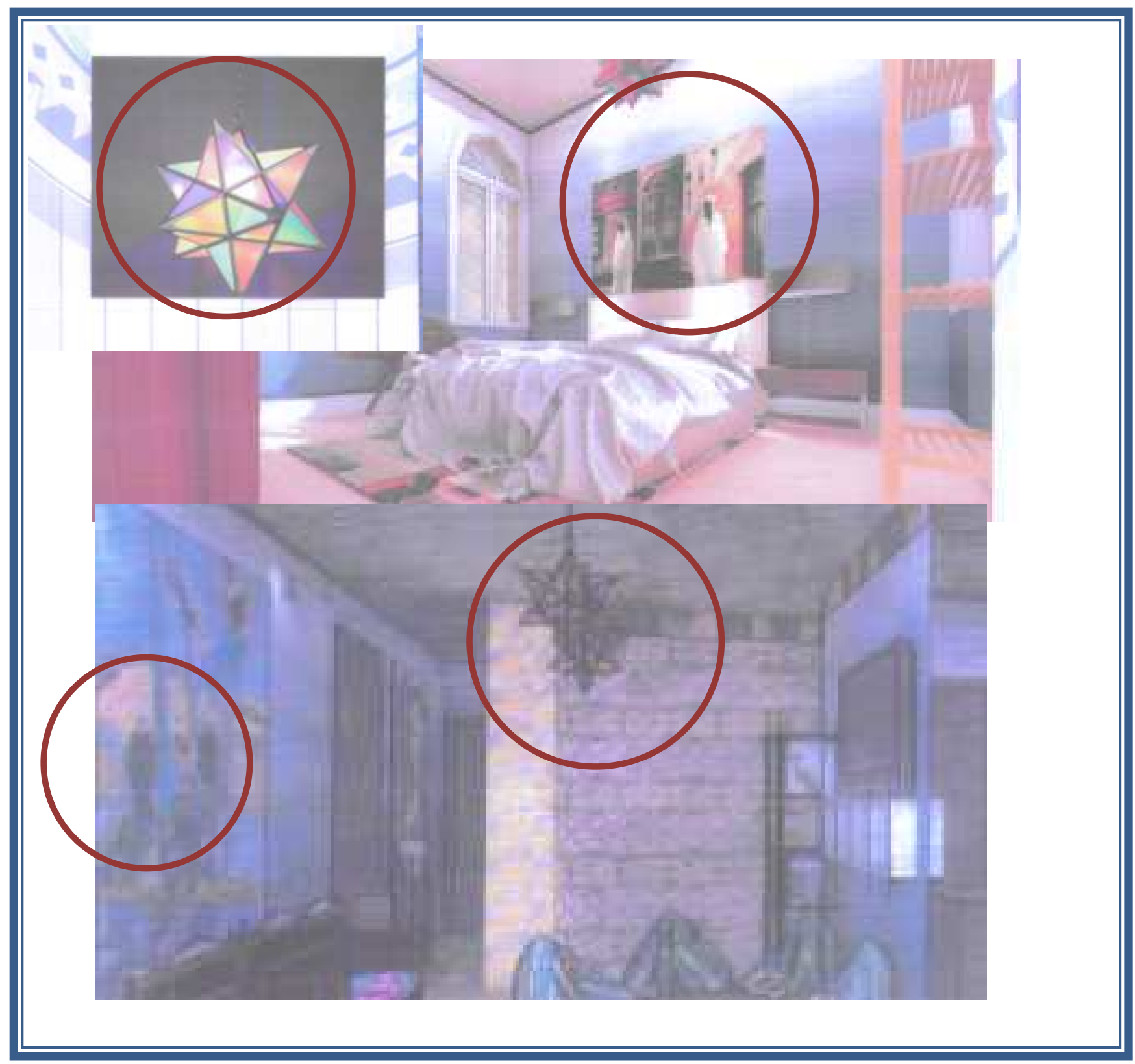

شكل (بّم) اللوحات ووحدات الأضاءة كمكلات للتصميم الاخلى ( من عمل الباحثه ). . . 


$$
\text { • المقترح الثانى }
$$

ا-معالجات التصميم الداخلى للمسقط الأفقى .

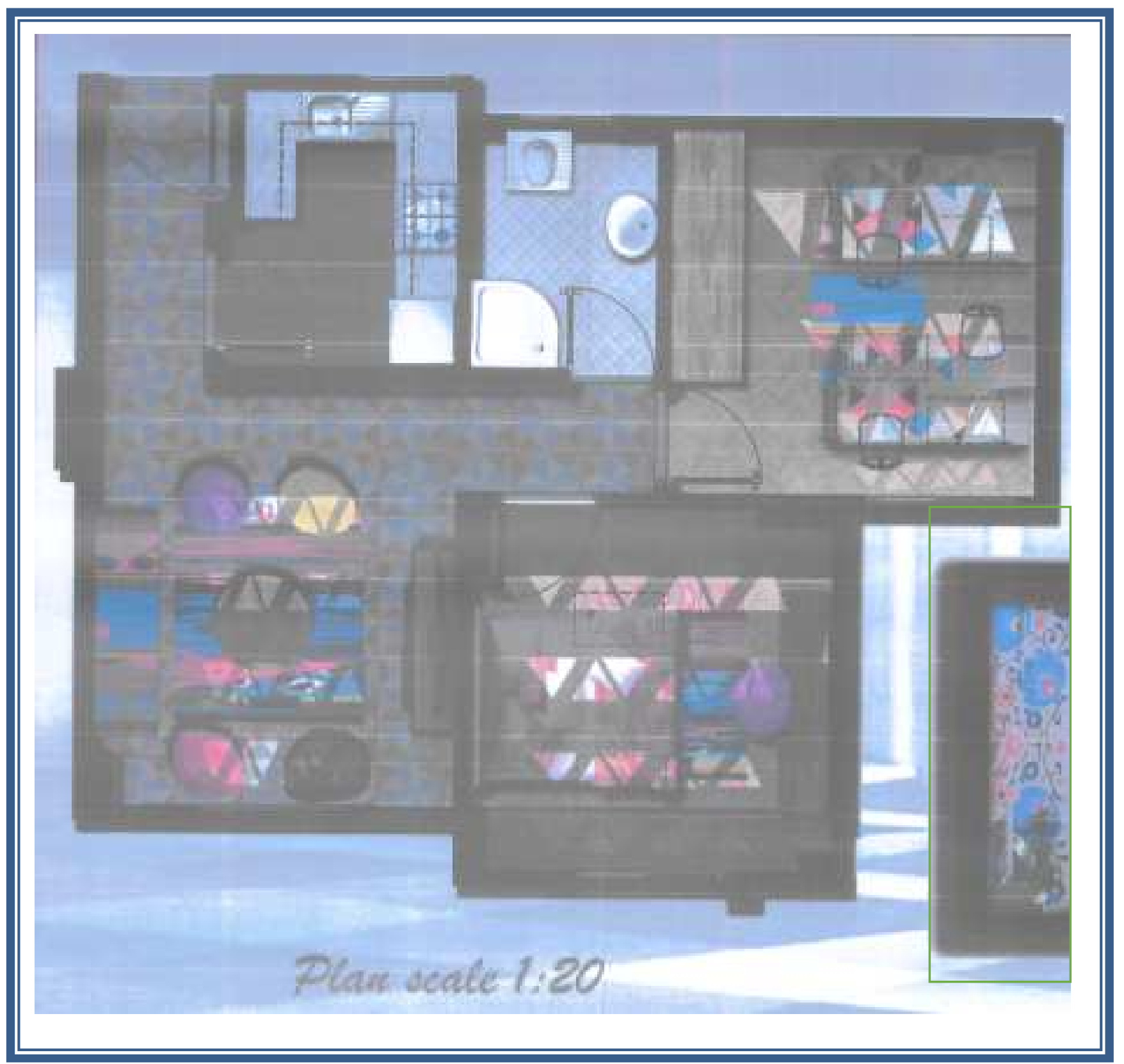

شكل ( ع ب) أستخدام التصميم الداخلى للمسقط الأققى ،ونجد اندماج انعكاس الأضاءة من الفتحات مع عناصر التصميم الداخلى .

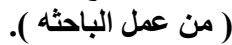


| إمعالجات التصميم الداخلى للحوائط الاخلية .

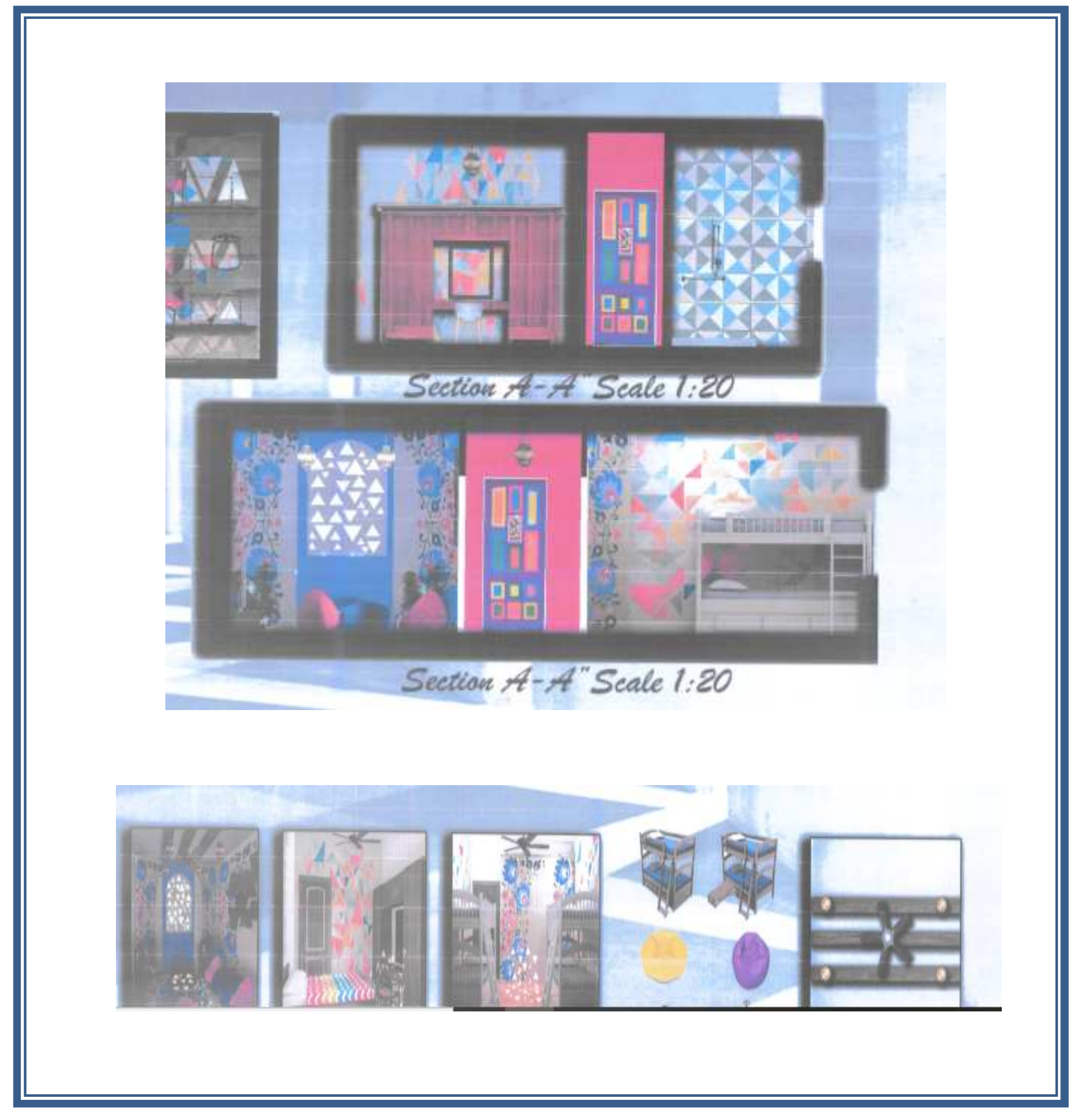

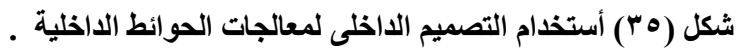

( من عمل الباحثة ). 


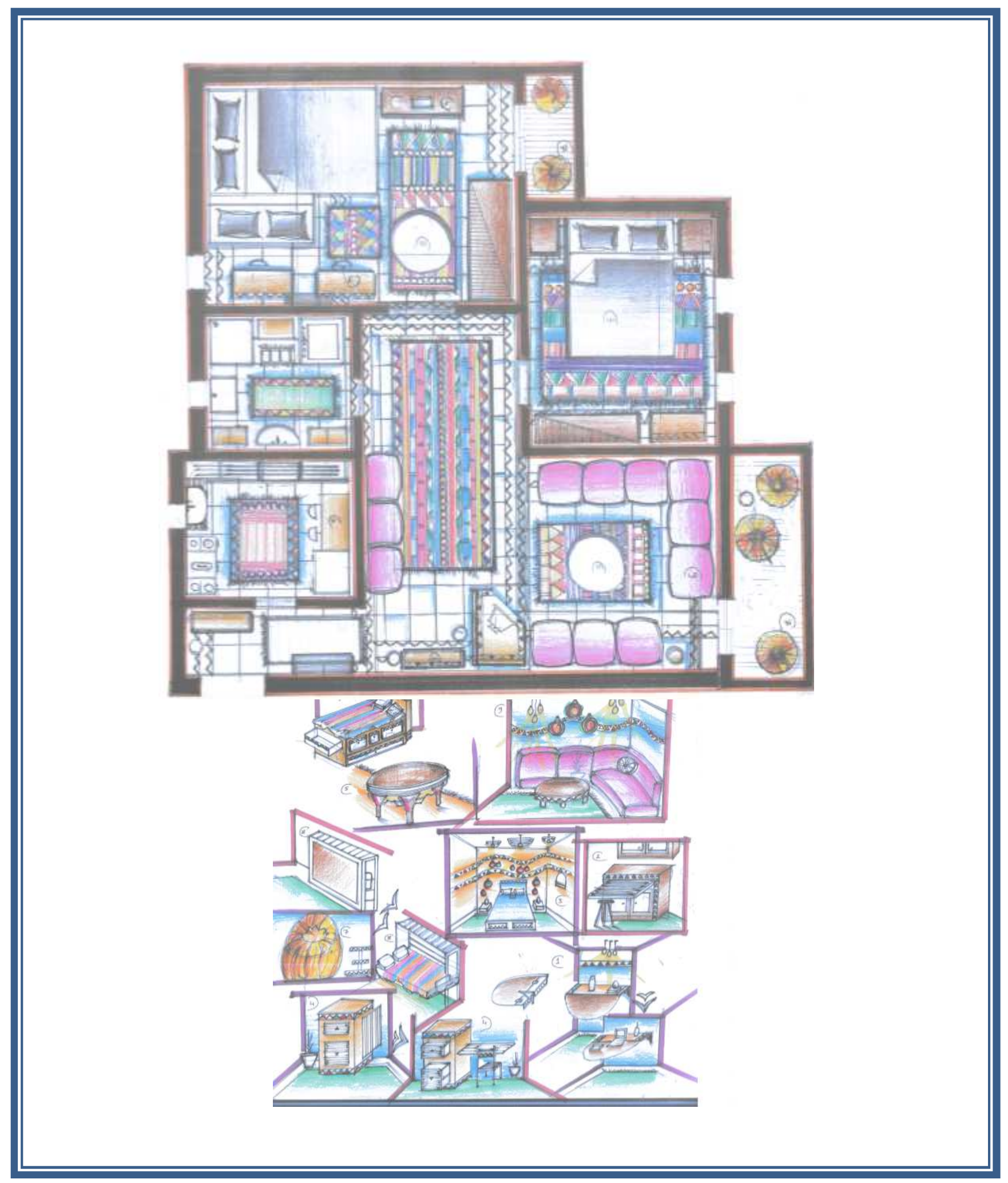

شكل ("^r) أستخدام التصميم الداخلى لمعالجات الحوانظ الاخلية . 
ا_معالجات التصميم الاخلى للمسقط الأفقى .

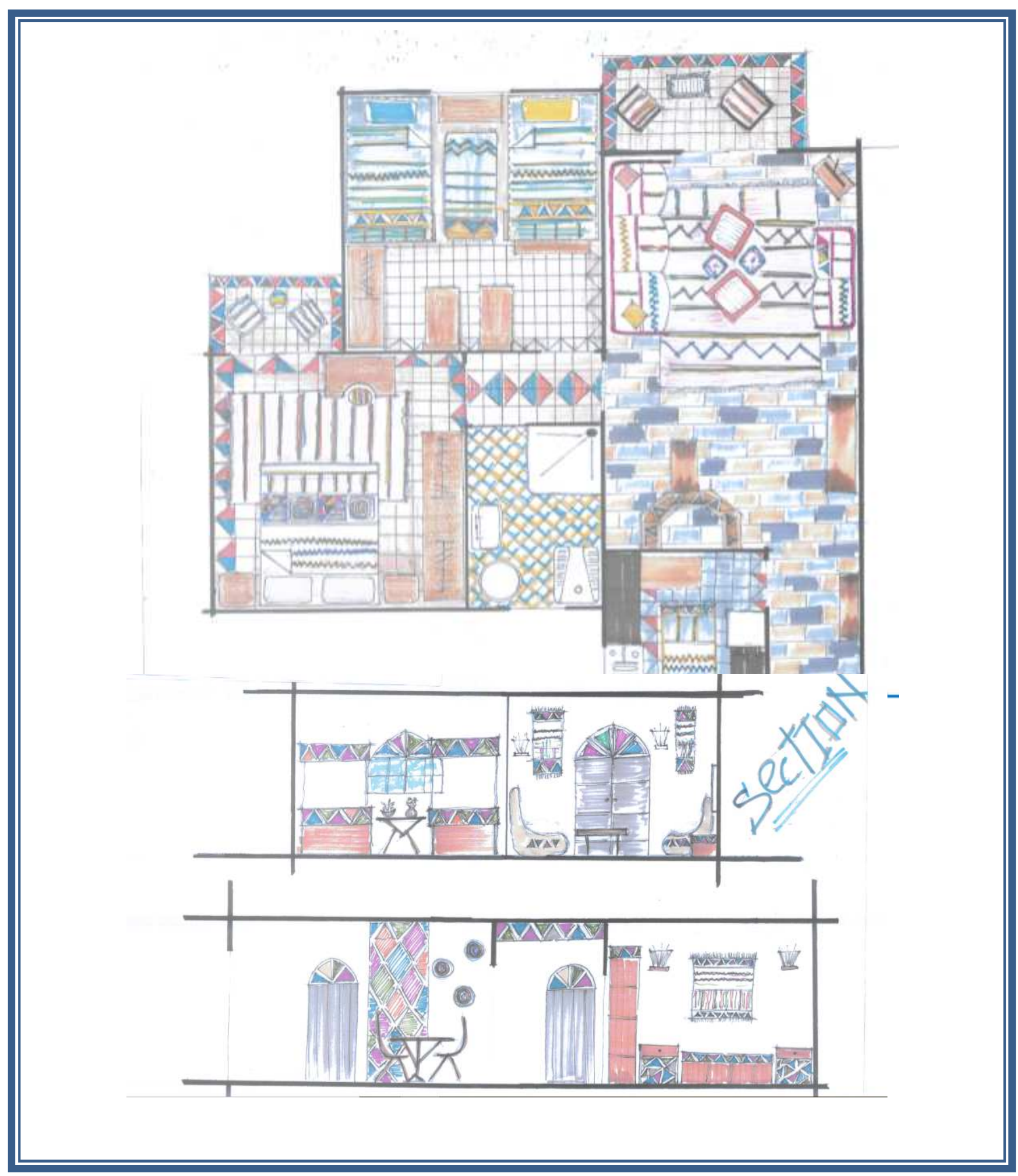

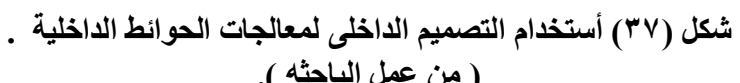

( من عمل الباحثّه ). 
أـ ـتناول هذا البحث دراسة نماذج من المساكن بأسوان بأعنبار ها من المناطق ذات الطابع الحضرى و النقافى المميز

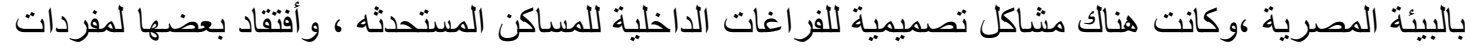

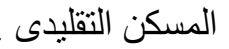

r- التصميم الداخلى الجيد لأى حيز يجب ألا يكون منفصل عن المجتمع المحيط به ، و المفردات البيئية المميزه لـه

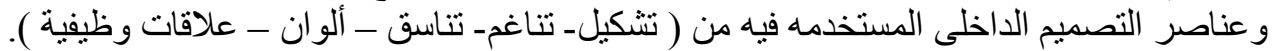

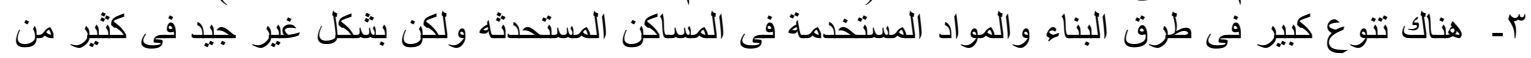

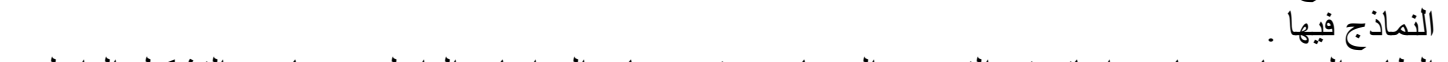
عـ ـ الطابع الحضارى هام مر اعاته فى التصميم المعمارى وتصميمات الفر اغات الداخليه و عناصر التشكيل الداخليه . .

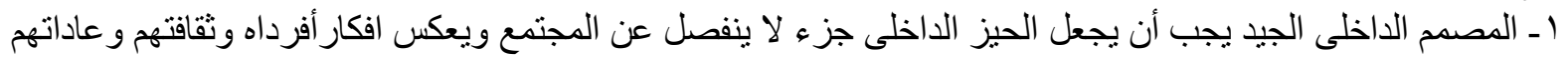

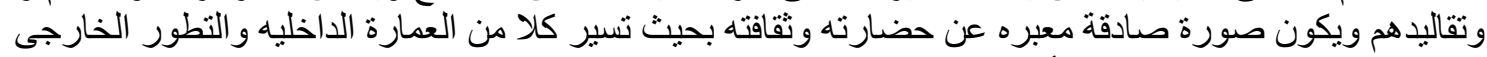

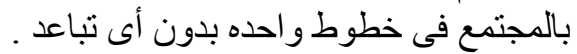

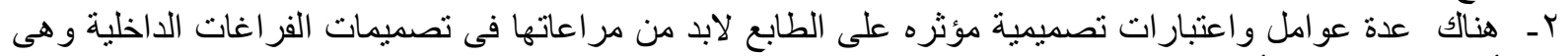

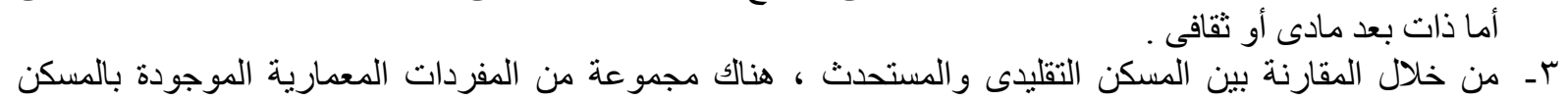

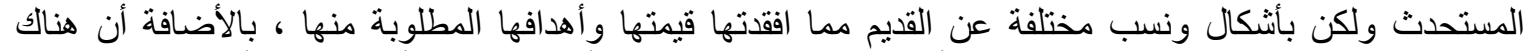
مجموعة من هذه المفردات غير موجوده مما أفقدت هذا المسكن مبادئه الأجتماعية التى أنشىء على على أساسها .

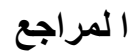

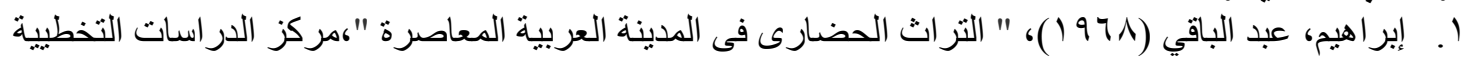

أولا: الكتب العلمية .

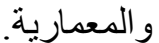

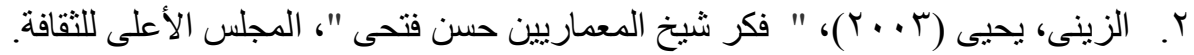

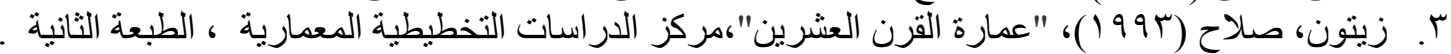

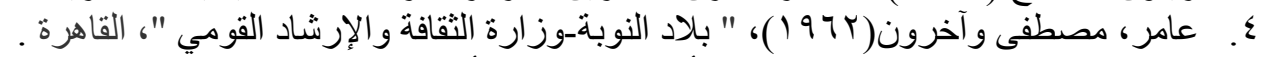

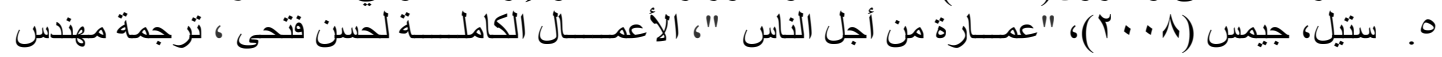

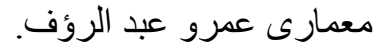

\section{ثانيا: الرسائل العلمية .}

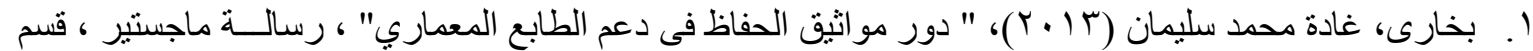

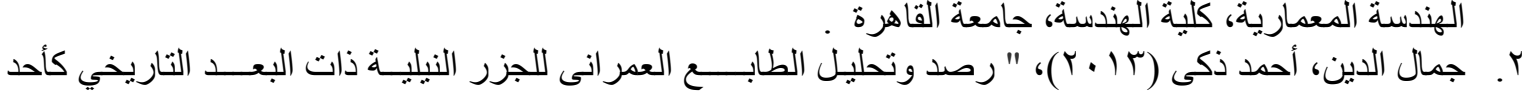

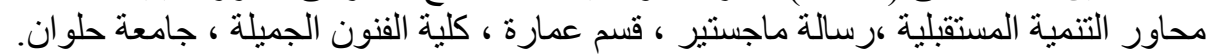

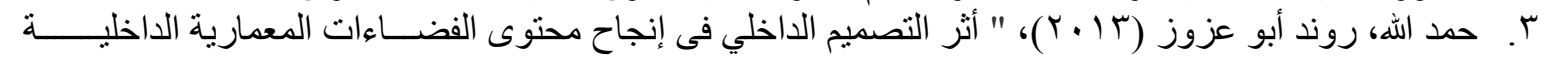

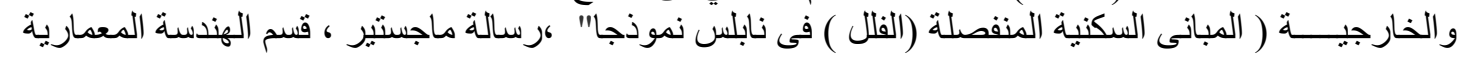

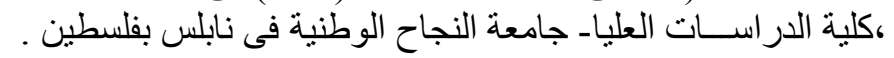

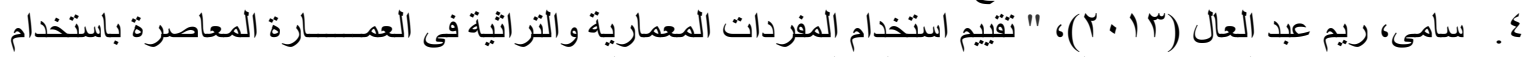

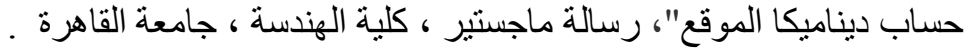

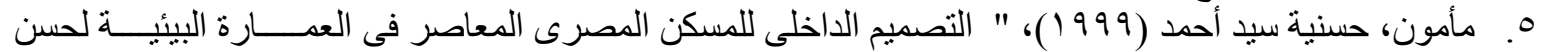

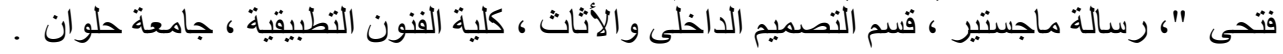

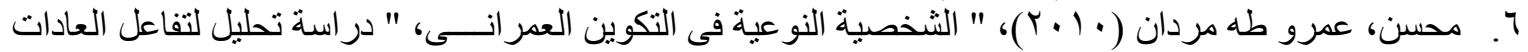

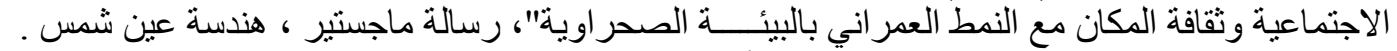

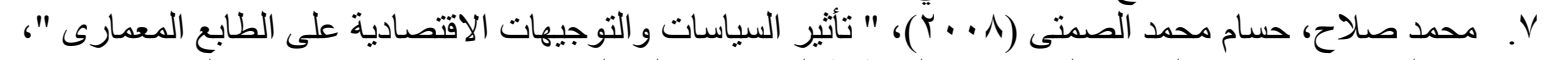

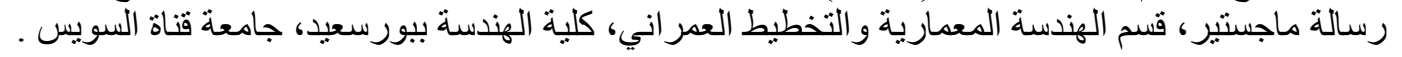

